\title{
ARQUITECTURA, MEMORIA Y FUTURO. LA MEZQUITA-CATEDRAL DE CÓRDOBA*
}

Michele Lamprakos

University of Maryland-College Park

ORCID: https://orcid.org/0000-0002-9581-2145

\section{RESUMEN}

La Gran Mezquita de Córdoba es uno de los monumentos más importantes de la civilización islámica y un famoso sitio en la lista del Patrimonio Mundial. Sin embargo, durante casi ocho siglos ha servido como la catedral de la ciudad. En tanto que otras mezquitas en la península Ibérica fueron finalmente demolidas y reemplazadas por iglesias y catedrales en algún momento posterior a la conquista castellana, la Gran Mezquita de Córdoba sobrevivió. Fue modificada para el culto católico, en una adaptación que culminó con la inserción de un gran coro y un presbiterio (crucero) en el siglo XVI. Esto produjo una imagen curiosa y dual que ha confundido, perturbado y fascinado a los visitantes durante siglos: el edificio es una catedral, pero parece una mezquita. Tras la inserción del crucero, la estructura fue progresivamente "cristianizada", aunque solo para ser "re-islamizada" en los siglos XIX al XX. El intento actual de la Iglesia por afianzar su control, y la resistencia que esto ha provocado entre los activistas ciudadanos, es solo el último episodio de una extraordinaria historia de 800 años. La confrontación sobre la fábrica e interpretación del edificio testimonia la poderosa continuidad del legado arquitectónico islámico. Pero también es un barómetro del cambio de actitudes hacia el pasado islámico, y el significado de ese mismo pasado para la cultura y la sociedad españolas.

Palabras clave: Gran mezquita de Córdoba, pasado islámico, Iglesia católica, patrimonio, memoria histórica

\section{ABSTRACT}

The Great Mosque of Cordoba is one of the foremost monuments of Islamic civilization and a famous World Heritage site. But for almost eight centuries, it has served as the city's cathedral. While other mosques on the Iberian peninsula were eventually demolished and replaced by churches and cathedrals at some point after the Castilian conquest, the Great Mosque of Cordoba survived. It was modified for Catholic worship, culminating in the insertion of a massive choir and presbytery (crucero) in the sixteenth century. This produced a curious, dual image that has confused, disturbed and fascinated visitors over the centuries: the building is a cathedral, but it looks like a mosque. Following the insertion of the crucero, the fabric was progressively "christianized" -only to be "re-islamicized" in the 19th-20th centuries. The Church's current attempt to tighten its hold, and the resistance this has provoked among citizen activists, is just the latest episode in a remarkable 800-year story. The struggle over the fabric and interpretation of the building attests to the continuing power of the Islamic architectural legacy. But it is also a barometer of changing attitudes toward the Islamic past - and the meaning of that past for Spanish culture and society.

Keywords: Great Mosque of Cordoba, Islamic past, Catholic Church, Heritage, Historical memory 
Córdoba es una ciudad de fantasmas. Por supuesto, se podría decir que España es un país de fantasmas, pero su presencia se percibe más intensamente en el sur, la región que concentra, en gran medida, el alma trágica o pathos de la nación. Desde finales del siglo XIX estos fantasmas han estado presentes en los intentos modernos por salvar el patrimonio de la ciudad y atraer turismo. Las primeras zonas de la ciudad histórica de Córdoba fueron reconocidas y protegidas por su valor patrimonial en fecha tan temprana como el año 1912; el objetivo, en palabras del alcalde por entonces, era

para perpetuar y sostener en lo posible el carácter típico de nuestra población en los distritos que por la clásica estructura de sus calles y el aspecto que presentan en conjunto, evocan la memoria de extinguidas razas $y$ de acontecimientos de lejanas épocas excitando la curiosidad de los que los visitan.

Resulta que cuando comenzaron los proyectos de conservación patrimonial, estas "extinguidas razas", musulmanes y judíos, habían estado ausentes de la península desde hacía cientos de años. Fueron convertidos por la fuerza y finalmente expulsados a comienzos de la época Moderna, como parte del proceso de creación de un Estado unificado y completamente católico. ${ }^{2}$ Sin embargo, estas presencias ausentes rondan por la ciudad y el paisaje circundante en rasgos como los inusuales trazados de iglesias, en deuda con los planos de las mezquitas sobre las que se construyeron; alminares escondidos dentro de los campanarios; edificios que se rumorea que fueron sinagogas; nombres de calles que evocan el pasado árabe-islámico de la ciudad, y otros

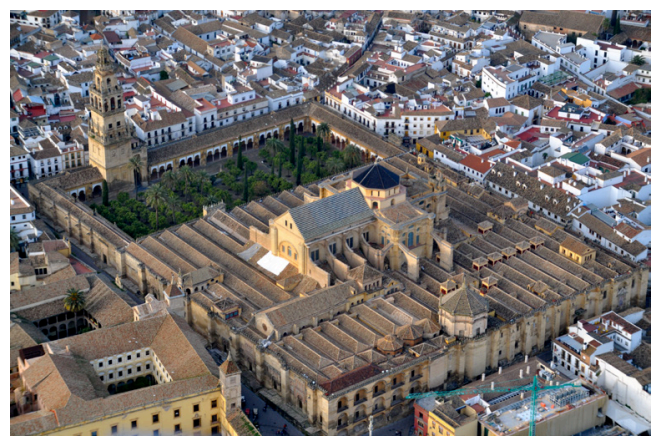

Fig. 1. Vista aérea de la Mezquita-Catedral de Córdoba, 2010. Fotografía cortesía de tonicastillo.com que recuerdan las atrocidades de la Inquisición. Otros fantasmas son más recientes: monasterios vacíos expropiados por el Estado liberal en el siglo XIX; estatuas decapitadas en iglesias atacadas por tumultos anticlericales durante la Guerra Civil; o las tumbas sin señalar de las víctimas del reinado de terror de Franco. El llamado "pacto del olvido" que acompañó la transición española hacia la democracia, en cierto sentido sirve para caracterizar toda la historia andaluza. ${ }^{3}$ La historia, o más bien las historias particulares, han sido repetidamente sepultadas, sólo para ser parcialmente excavadas y luego enterradas otra vez en un nuevo ciclo de olvido.

Un destacado edificio se alza como si fuera un desafío en el corazón de Córdoba: la llamada Mezquita-Catedral (fig. 1). Considerado uno de los grandes monumentos de la arquitectura mundial, es el reclamo más famoso de la ciudad,

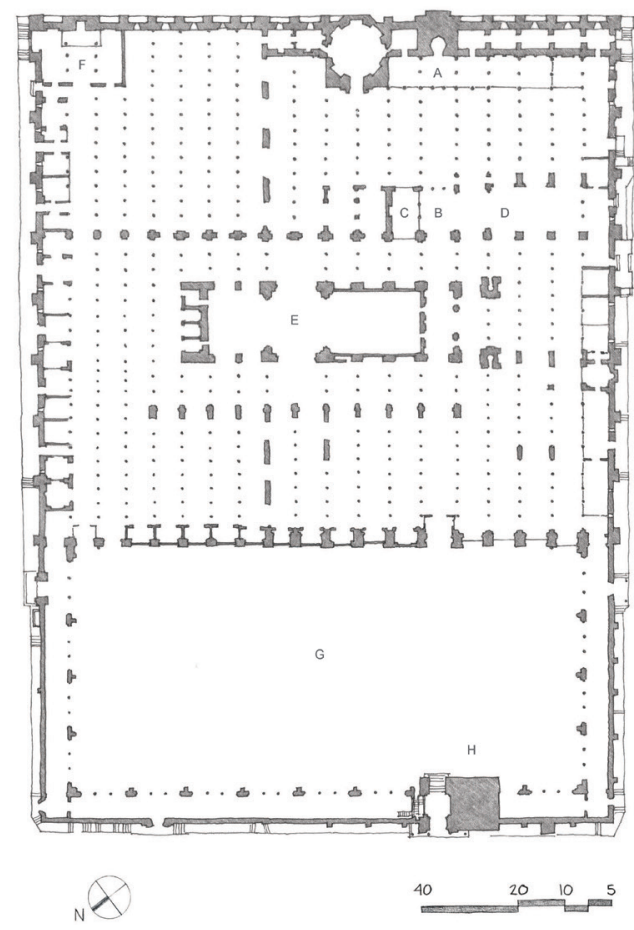

Fig. 2. Plano esquemático de la Mezquita, en su situación actual. $A$, mihrab y maqsura de la ampliación de al-Hakam; $B$, Capilla de Villaviciosa (vestíbulo de al-Hakam/antigua capilla mayor); C, Capilla Real; D, Nave "Gótica" (completada ca. 1496); E, Crucero (comenzado ca. 1523); F, Sagrario; G, Patio de los Naranjos; $H$, Torre campanario/restos del minarete. Plano realizado por la autora, de acuerdo con diferentes fuentes 


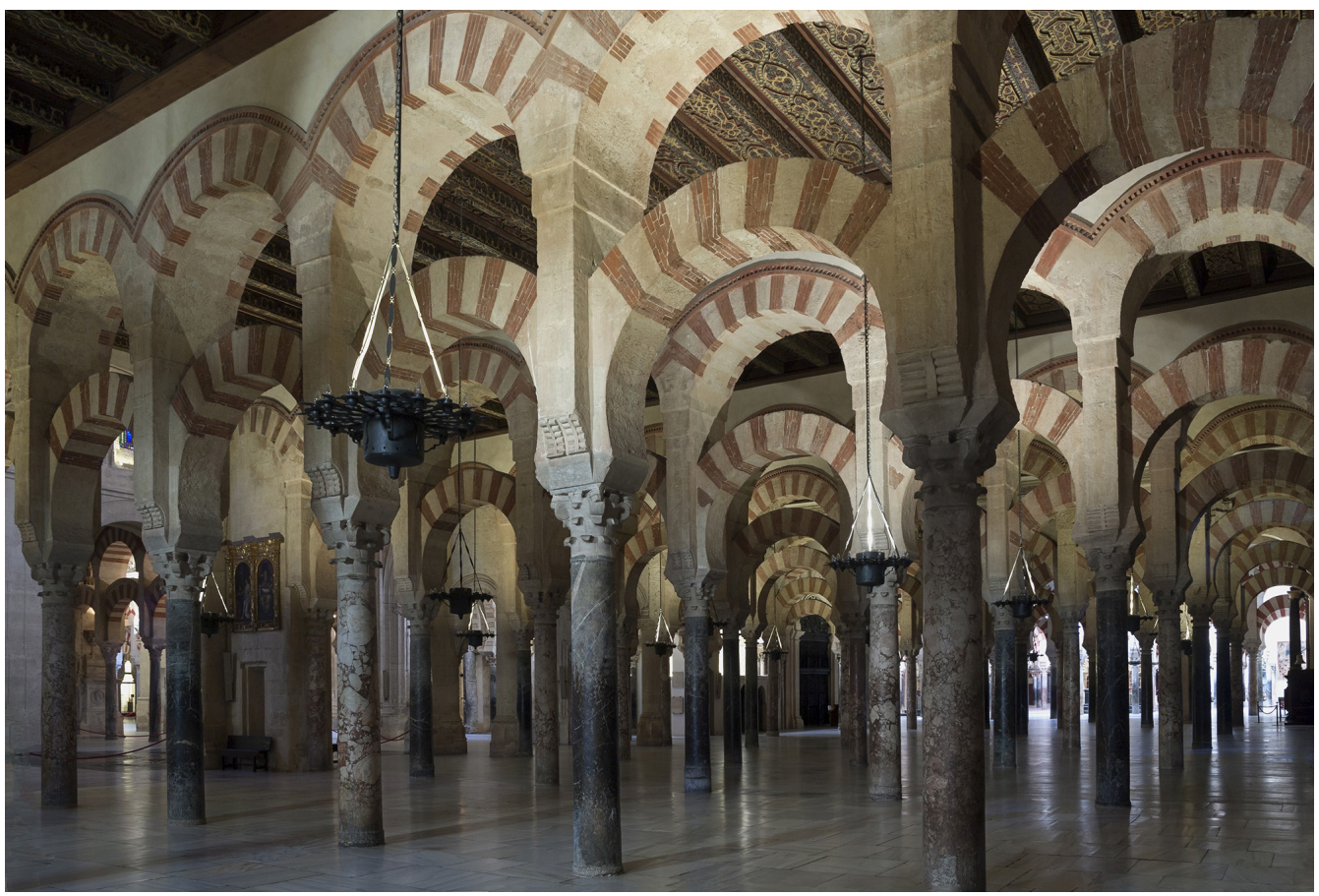

Fig. 3. Vista del interior desde la parte sudoeste del edificio en dirección hacia el nordeste

una fuente de orgullo y riqueza, pero también de ansiedad. Aunque el edificio ha sido una catedral durante casi ocho siglos, la mayoría de los lugareños todavía se refieren a él como "la Mezquita". En los últimos años la Iglesia Católica ha tratado de cambiar eso, desencadenándose una creciente polémica por el control y el significado del edificio entre la Iglesia y activistas ciudadanos. La intensidad de la disputa es sorprendente para los forasteros teniendo en cuenta los problemas acuciantes que afectan a la región, en particular una desesperada situación económica que ha dejado a toda una generación sin trabajo y en un futuro incierto, alimentando una nueva ola de emigración andaluza hacia otras partes de España y el extranjero. Solo gradualmente uno se da cuenta de que el conflicto sobre la Mezquita tiene tanto que ver con el presente como con el pasado. De hecho, las dos épocas están íntimamente entremezcladas. La historia de fondo del conflicto está tejida con hilos entrelazados, todos los cuales se pueden referir, directa o indirectamente, a las propias capas históricas constructivas del edificio en sí mismo.
La Mezquita es la más magnífica de las mezquitas del Viernes o mezquitas congregacionales que fueron el centro de la vida religiosa y cívica bajo el dominio islámico, el cual se mantuvo en varias formas en la península durante unos siete siglos (entre los siglos VIII al XV). Cuando los ejércitos de la corona de Castilla comenzaron a conquistar ciudades (siglos $\mathrm{XI}$ al XV), consagraron aquellas mezquitas para el culto cristiano. En el transcurso de los siglos, las demolieron y construyeron en su sitio catedrales, en un proceso que reproducía la apropiación de los lugares sagrados cristianos por parte de los musulmanes en España y en otros países. ${ }^{4}$ Pero la mezquita de Córdoba sobrevivió. Con el paso de los siglos se modificó para el culto católico, culminando con la inserción en el siglo $\mathrm{XVI}$ de un enorme coro y un presbiterio, la estructura que suele denominarse coro-crucero, o simplemente crucero. Las intervenciones cristianas en unas ocasiones aprovecharon y en otras dieron réplica a las cualidades estructurales, espaciales y simbólicas de la mezquita. Como en otras catedrales, estas intervenciones estuvieron motivadas por nuevas necesidades litúrgicas y cambios en los gustos estéticos. ${ }^{5}$ Pero la de Córdoba no es 


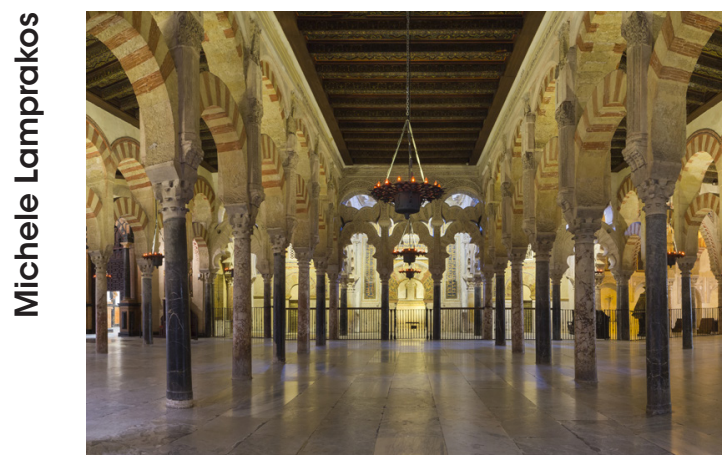

Fig. 4. Ampliación de al-Hakam en dirección sur hacia el mihrab y maqsura

cualquier catedral. Es una catedral alojada en la antigua Gran Mezquita de Córdoba, un edificio que simboliza el Islam en el apogeo de su poder en Europa. A lo largo de los siglos la Mezquita ha sido un lugar de culto, un monumento querido y también un potente recordatorio del pasado islámico. Podemos leer los ciclos de protección, demolición y restauración como un indicador de las cambiantes actitudes hacia ese pasado y el espectro de lo "Moro": una imagen recurrente de sí mismo y del otro en la historia de España. ${ }^{6}$

\section{Un edificio "único en el mundo"}

La Gran Mezquita fue construida en varias etapas bajo la dinastía de los Omeyas que, exiliada desde Siria, estableció un poderoso imperio en la península Ibérica (entre los siglos VIII y XI). La mezquita original de Abd al-Rahman I (784-785) se amplió dos veces al mover el muro de la qibla hacia el sur, es decir, hacia el río. Con la posterior expansión de al-Mansur hacia el este (circa 987), la mezquita alcanzó un tamaño sin precedentes (fig. 2). ${ }^{7}$ Ahora bien, cada ampliación mantuvo una continuidad con la estructura y morfología originales: dos niveles de arcos, alternando en las dovelas el ladrillo rojo con la piedra blanca, corren en perpendicular hacia el muro de la qibla; a su vez, los arcos están soportados por columnas de mármol de varios colores, reutilizadas de sitios antiguos o de nueva fabricación. ${ }^{8}$ El resultado es un fantástico interior, similar a un laberinto, que presenta al visitante vistas infinitas y en constante cambio (fig. 3). En los siglos posteriores los cronistas españoles no dejaron de aludir al espacio como un bosque de columnas, destacando implí-

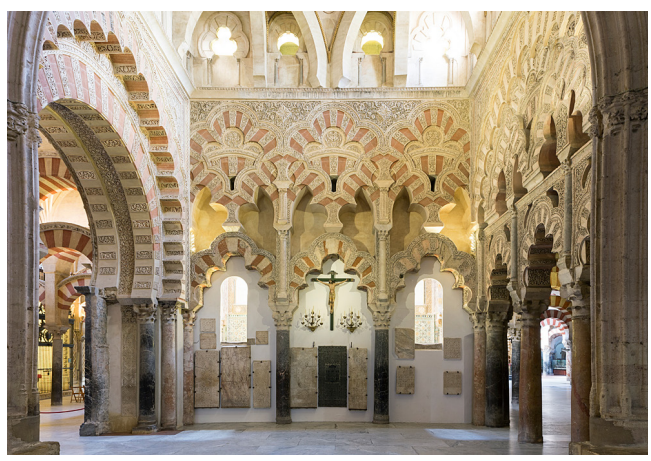

Fig. 5. Entrada a la ampliación de al-Hakam (Capilla de Villaviciosa/antigua capilla mayor) en dirección este.

citamente el contraste con las formas más finitas y jerarquizadas de la arquitectura de sus iglesias. El espacio hipóstilo está anclado en el cuadrante sudoeste por la magnífica ampliación de alHakam, completada en 976. Las tres crujías de la maqsura (recinto real) se corresponden con tres aberturas arqueadas en el muro de la qibla, de manera que el arco central y más grande enmarca el mihrab, que toma la forma de una pequeña habitación. Las crujías de la maqsura y el vestíbulo de la ampliación están cubiertos con cúpulas de lucernarios y parcialmente cerrados por arcos entrelazados. Esta configuración de tipo basilical tiene precedentes tanto en la arquitectura palaciega como en la religiosa (fig. 4). ${ }^{9}$

Cuando el rey Fernando III tomó Córdoba en 1236, la Mezquita fue consagrada como iglesia por medio de los tradicionales rituales de purificación, quedando dedicada a la Virgen María. Varios años después fue elevada a la categoría de catedral. ${ }^{10}$ Durante dos siglos y medio el ceremonial y el mecenazgo de los cristianos se centraron en la ampliación de al-Hakam, tal vez porque la arquitectura, la decoración y el simbolismo presentaban reminiscencias con una iglesia. Como los musulmanes habían concebido la basílica de al-Hakam como una "mezquita dentro de una mezquita", es posible que los cristianos la vieran como "iglesia dentro de una iglesia". ${ }^{11}$ Se ha asumido que la orientación litúrgica se cambió inmediatamente hacia el este, pero la ubicación del ceremonial de dedicación es desconocida. Para algunos historiadores la situación del primer coro de la catedral estaba en la nave frente al mihrab, con un altar dedicado a San Pedro. Solo 
después de 1257, bajo el patrocinio de Alfonso $X$, se construyó una capilla mayor en el vestíbulo de al-Hakam, con el altar orientado hacia el este (fig. 5). ${ }^{12}$ Durante más de tres siglos, la hostia consagrada se guardaría en el mihrab, de manera que la parroquia de Santa María tendría su lugar de culto en la nave del mihrab, orando hacia el sur como hicieran los musulmanes. ${ }^{13}$

La insospechada supervivencia de la Mezquita, tema de mucha especulación por parte de especialistas y no especialistas, se suele atribuir a su gran belleza y prestigio. ${ }^{14}$ En su descripción de la ciudad a mediados del siglo XV, un monje cordobés exaltó el edificio como

...un templo merecedor de toda clase de alabanzas en cuya vistosísima hermosura reanima el espíritu del que lo contempla. Es gloria de España y señal distintiva del honor de Córdoba, inclita sede de su Obispo y monumento que honra a los reyes, alivio de los fieles, e injuriosa venganza digna de lágrimas, para sus antiguos poseedores...

¿Acaso la artística construcción de tan gran edificio moverá a admiración no sin causa a los hombres que contemplan la multitud y altura de las columnas de mármol? El talento de los arquitectos determinó de tal modo su ordenadísima estructura que a cualquier parte que se mire la vista marcha majestuosamente...

"Qué queda por decir de este templo famoso?" -continúa el monje- "Los historiadores refieren los atributos prodigiosos solamente de siete obras en la tierra... Pero ¿quién apreciará en adelante que estos monumentos son los que destacan sobre los demás cuando contemple tal templo en nuestra ciudad?". ${ }^{15}$ De este modo, la Mezquita fue alabada tanto por cristianos como por musulmanes como una de las maravillas del mundo. Se reconoció como el gran ejemplo del estilo hispano-islámico, el estilo más prestigioso de la época, y se convirtió en un modelo para iglesias y mezquitas, en la península lbérica y más allá.

Durante dos siglos y medio la Mezquita disfrutó de protección y mecenazgo reales, en particular la Capilla Real del siglo XIV, como celebrada muestra de la arquitectura "mudéjar". ${ }^{16}$ Esta situación comenzó a cambiar con la reanudación de la "Reconquista" a finales del siglo XV y la consolidación gradual de una España unificada

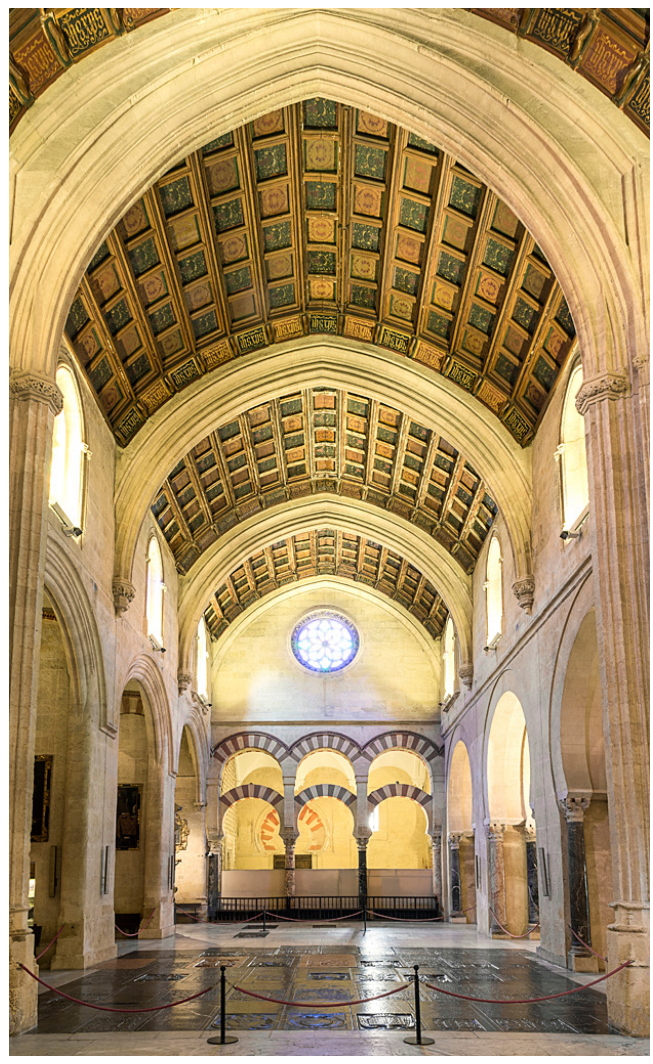

Fig. 6. La nave "Gótica", completada ca. 1496, en dirección oeste

y católica. Ante la inminente caída de Granada, el obispo de Córdoba, Íñigo Manrique de Lara (1485-1496), presentó un plan para transformar la Mezquita. El proyecto, al que supuestamente se habría opuesto la reina Isabel, desembocó en un compromiso: se construyó una nave de estilo gótico en el área de la ampliación de al-Hakam, extendida hacia el oeste desde el altar (fig. 6). ${ }^{17}$ En las décadas siguientes, la oleada de victorias militares y el auge económico del reino cristiano permitieron construir nuevas grandes catedrales; algunas de ellas se levantaron en los sitios de mezquitas que habían sido recientemente incautadas en Andalucía. ${ }^{18}$ La enorme catedral de Sevilla, en el sitio de la antigua mezquita almohade del Viernes, había estado en obras de construcción durante más de un siglo, aproximándose por entonces a su terminación. Fue en este contexto cuando el obispo Alonso Manrique de Lara (1516-1523), primo hermano de Î́nigo, presentó 


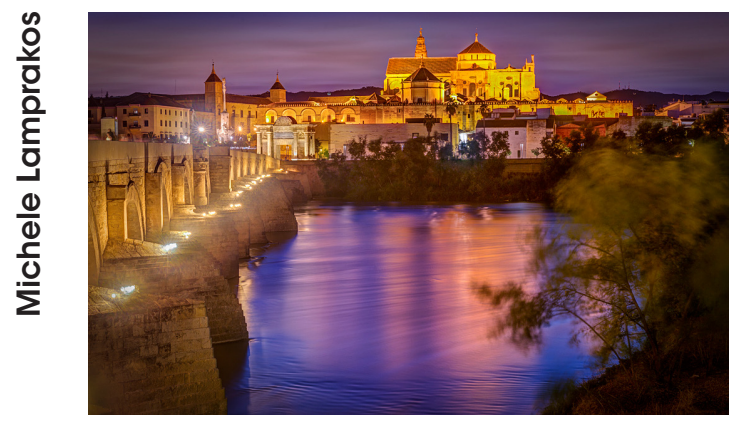

Fig. 7. Vista de la Mezquita desde el río Guadalquivir

una segunda propuesta para transformar la Mezquita. A finales de la primavera de 1523, cuando la obra de demolición dio comienzo, el concejo lanzó una decidida protesta, apelando hasta el emperador Carlos V. El proyecto finalmente fue adelante, tal vez reducido frente al plan original. Cuando el emperador contempló en 1526 el resultado de la demolición habría dicho:

Yo no sabía, que era esto; pues no huviera permitido, que se llegase à lo antiguo; porque haceis lo que puede haver en otras partes, y haveis deshecho lo que era singular en el mundo. ${ }^{19}$

El comentario apócrifo de Carlos $\vee$ podría derivar de una declaración realizada por el ayuntamiento en 1523: el nuevo proyecto, escribieron entonces, destruiría un templo que era "único en el mundo". ${ }^{20}$

El impresionante crucero, completado un siglo después, transformaría la imagen del edificio en el horizonte (fig. 7). Ahora bien, dentro del edificio, curiosamente la fábrica de la Mezquita aparentaba permanecer intacta. Una inspección más detallada revela que el arquitecto inicial, Hernán Ruiz I, envolvió el crucero en un nuevo "deambulatorio" al decidir replicar algunos de los arcos de la era islámica que había demolido, reutilizando las mismas piedras, columnas y capiteles. ${ }^{21}$ La sustitución de las partes viejas por las nuevas solo se evidencia cuando se mira hacia arriba en las bóvedas de crucería, o bien cuando se observan los discretos detalles decorativos. En efecto, Hernán Ruiz disfrazó el crucero por dentro, suavizando la nueva y extraña inserción (figs. 8 y 9). Esto produjo una curiosa imagen dual, que ha confundido, perturbado y fascinado a los

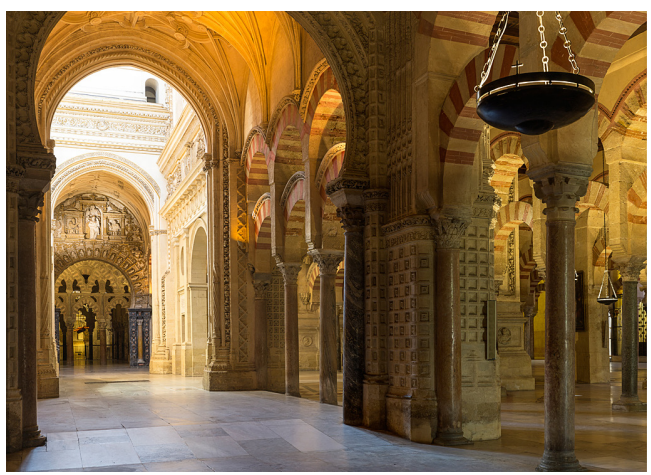

Fig. 8. La esquina noroeste del crucero en dirección sur hacia la ampliación de al-Hakam. Se pueden observar las bóvedas nervadas que distinguen la nueva intervención de la fábrica de la mezquita a su alrededor

visitantes durante los siglos: el edificio es una catedral, pero parece una mezquita.

Durante los siglos venideros, de hecho hasta el día de hoy, los visitantes y cronistas han repetido los comentarios apócrifos de Carlos V, lamentando que aquel edificio único hubiera sido mutilado. En cambio algunos, como un diplomático procedente de Marruecos en el siglo XVII, informaron que la mezquita había permanecido esencialmente sin cambios. ${ }^{22}$ De hecho, los visitantes continuaron exaltando las infinitas vistas de la mezquita, que no parecían obstaculizadas por el crucero. En la actualidad la defensa del crucero implica entrar en un debate ideológico. Sin embargo, rara vez se advierte que la sensible inserción de Hernán Ruiz I preservó tanto la lectura de la mezquita como el recuerdo de un conflicto, en el preciso momento en que la presencia y legado cultural musulmanes se estaban borrando de la península.

\section{De la cristianización a la "re-islamización"}

La consagración del altar del crucero tuvo lugar en 1607, poco antes de que los descendientes de los musulmanes, los moriscos, fueran expulsados. ${ }^{23} \mathrm{~A}$ mediados del siglo XVII la base del alminar del siglo $X$, que se había convertido en una torre-campanario, fue forrada en piedra, perdiéndose finalmente para el recuerdo. En el siglo XVIII se completó una elaborada sillería de coro, en tanto que las dovelas rojas y blancas de los arcos quedaron encaladas y se abrieron unas bóvedas y lucernarios de estilo barroco que 


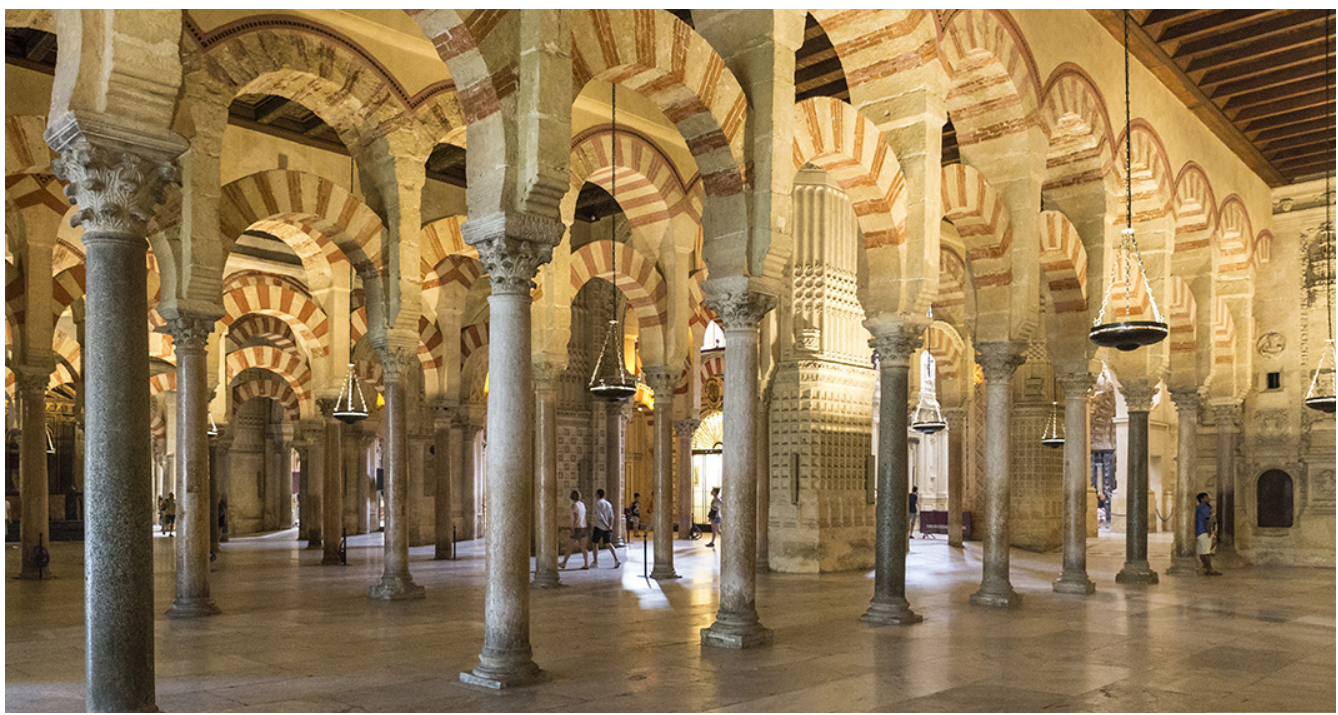

Fig. 9. Vista hacia los pilares en el norte del crucero desde el noroeste

inundaron de luz el espacio interior e integraron más intensamente el crucero (figs. 10 y 11).24 La "cristianización" de la fábrica de la mezquita parecía completada. Sin embargo, en el siglo XIX algunos obispos afrancesados, y posteriormente los arquitectos estatales, comenzarían a recuperar el edificio islámico. Así, se rescató el mihrab, se demolieron bóvedas barrocas, se despojaron de encalados los arcos y se quitaron capillas, retablos y tumbas. Las magníficas portadas de la fachada este fueron restauradas y parcialmente reconstruidas a principios del siglo $X X$, restableciendo la imagen islámica del edificio en la ciudad (fig. 12). ${ }^{25}$ Estas restauraciones hicieron posible para los contemporáneos imaginar el edificio como una mezquita -exactamente tal como la recrearon los artistas románticos, repleta con musulmanes orando frente al mihrab (fig. 13). Gran parte de la fábrica islámica que vemos hoy es producto de aquellas restauraciones de los siglos XIX y XX (figs. 14 y 4).

El proceso de "re-islamización", ${ }^{26}$ que duró un siglo y medio, se vió rodeado por matices políticos. Para algunos liberales la figura del moro era un héroe, un rebelde, un gobernante iluminado que presidía una sociedad floreciente y diversa antes de que fuera destruida por una alianza fanática entre la Iglesia y el Estado. ${ }^{27}$ En efecto, aquellos liberales celebraban el pasado islámico porque representaba una alternativa a la narrativa histórica dominada por la Iglesia. Después de que el edificio fuera declarado monumento nacional (1882), la comisión de monumentos provinciales, compuesta por una intelectualidad liberal, y a veces anticlerical, trabajó con los arquitectos estatales para recuperar el edificio islámico. Su demolición de capas de la historia cristiana en unas ocasiones fue apoyada y otras impugnada, por cargos de la Iglesia que necesitaban los fondos del gobierno para mantener y reparar la grandiosa estructura.

La recuperación del tejido islámico también se cruzó de manera sorprendente con las ambiciones coloniales de España en el norte de África y con la situación política de afloramiento de las identidades regionales. En la década de 1930, inspirados por la restaurada imagen islámica de la Mezquita y en respuesta a los llamamientos de los nacionalistas árabes, algunos republicanos argumentaron que se debería permitir otra vez a los musulmanes rezar en el edificio. Otros, en cambio, querían convertirlo en un museo. Incluso se registró una propuesta para desmontar y trasladar el crucero por completo, reconstruyendo las partes islámicas perdidas. Luego, en 1936, las tropas llamadas Nacionales se alzaron contra la República y el general Francisco Franco cruzó el estrecho de Gibraltar con la ayuda de legionarios 


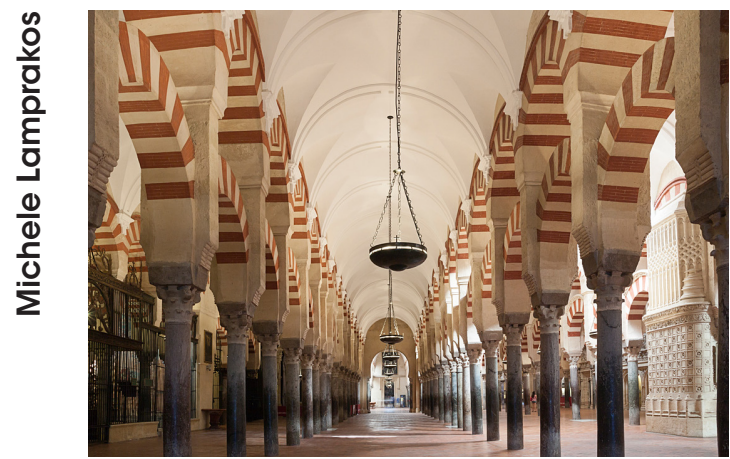

Fig. 10. Como parte de las bóvedas y lucernarios instalados en el siglo XVIII por todo el edificio, los que se aprecian en la fotografía se mantienen en la zona de la ampliación de al-Mansur

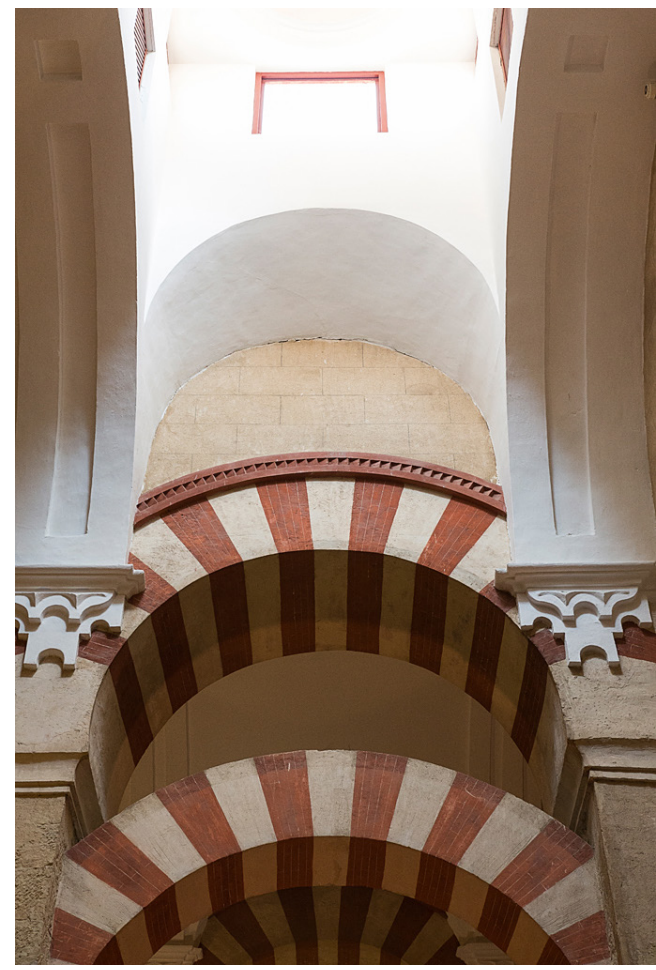

Fig. 11. Detalle de un lucernario en la ampliación de al-Mansur

marroquíes. Paradójicamente fue Franco, líder del nacional catolicismo, quien retomó la vieja idea republicana para tratar de convertir el edifico en una mezquita, como una forma de agradecer al mundo islámico su apoyo. ${ }^{28}$

Así, la Mezquita se convirtió en un peón diplomático en la política árabe del dictador, que, después de la independencia de Marruecos

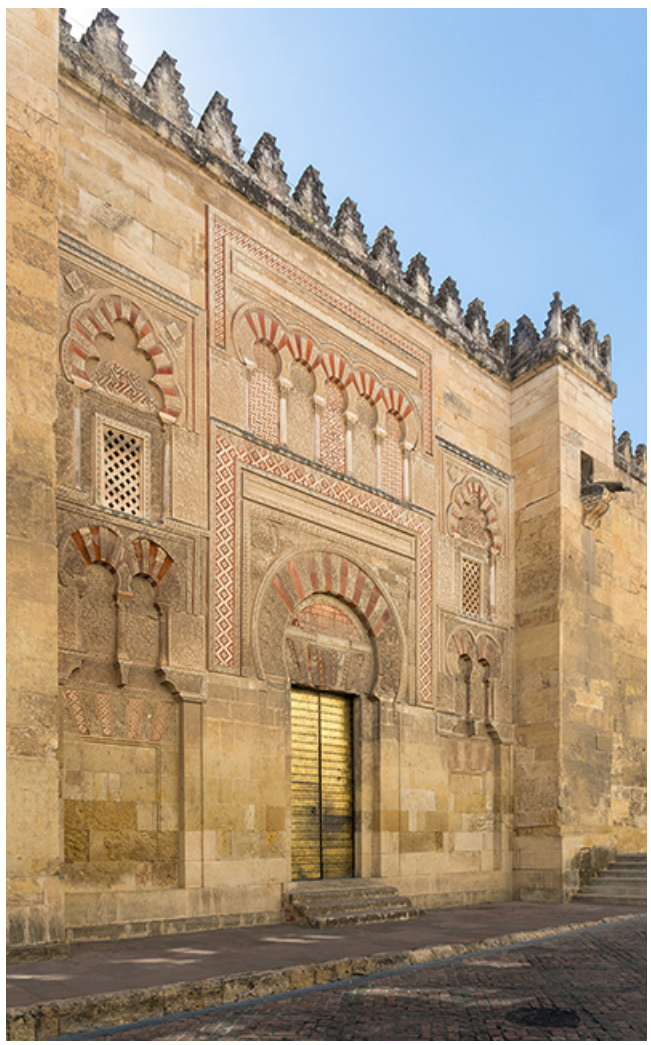

Fig. 12. Una de las portadas en la fachada este, restaurada y parcialmente reconstruida por Ricardo Velázquez Bosco, trabajando junto con el escultor Mateo Inurria, después de 1908

(1956), tuvo como objetivo fortalecer los lazos económicos con el mundo árabe. La propuesta de traslado del crucero se mantuvo viva tras las bambalinas durante décadas, estallando finalmente en una gran controversia pública en los últimos años del régimen. La idea liderada por Rafael de la Hoz Arderius, Director General de Arquitectura (1971-1973), con el apoyo del alcalde de Córdoba, Antonio Alarcón, el Ayuntamiento y miembros de la élite cultural y profesional, era "purificar" la Mezquita en preparación para una nominación a la nueva lista del Patrimonio Mundial. El traslado se debatió en la prensa cotidiana y en las páginas de Arquitectura, la revista de arquitectura más prestigiosa de España. Los distintos departamentos ministeriales por lo general apoyaron la propuesta, aunque la Iglesia y las instituciones culturales independientes se opusieron, en particular la Real Academia de Bellas Artes de San Fernando, el organismo históri- 


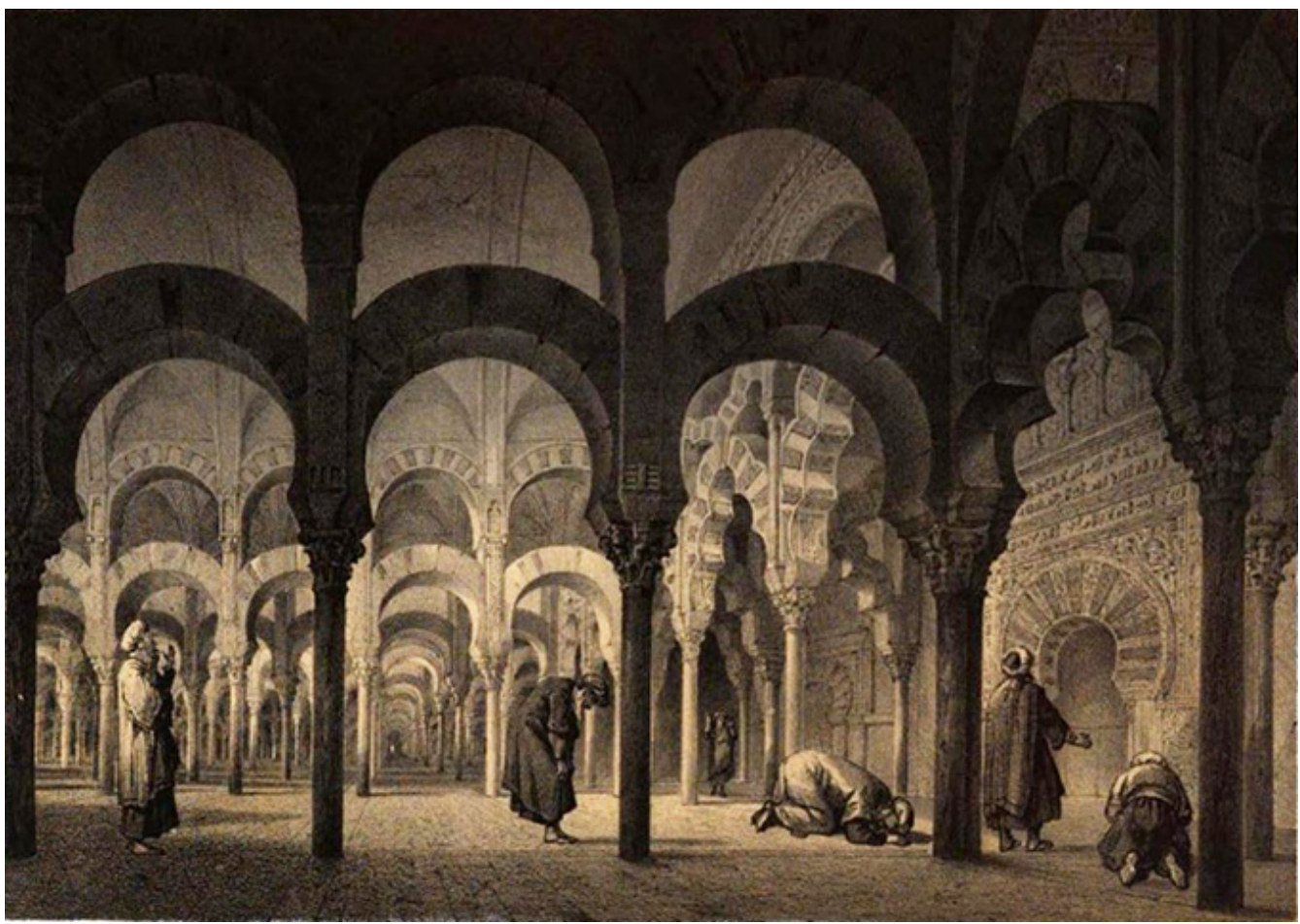

Fig. 13. Vista interior por Francisco Javier Parcerisa. Fuente: Recuerdos y Bellezas de España: Córdoba (Madrid: José Repullés, 1855)

camente encargado de supervisar el patrimonio español. En 1973, durante una conferencia de ICOMOS celebrada en la Mezquita, la opción del traslado fue aparentemente derrotada. Invocando la Carta de Venecia de 1964, la Iglesia y los representantes de ICOMOS argumentaron que el crucero era una capa arquitectónica importante y una evidencia de la convivencia religiosa y cultural. ${ }^{29}$ No obstante, en los años siguientes los ecos de la controversia sobre el traslado continuaron resonando en el cambiante panorama político.

\section{La Mezquita en Transición}

En la década de 1970 la Mezquita se convirtió en un espacio performativo para un nuevo espíritu ecuménico. Dos congresos islamo-cristianos se celebraron allí en 1974 y 1977, reuniendo juntos a eminentes teólogos y eruditos para discutir la relación histórica entre las dos religiones y trazar un camino de paz y entendimiento mutuo. Una oración congregacional islámica (salat) y una misa católica tuvieron lugar en la Mezquita, con

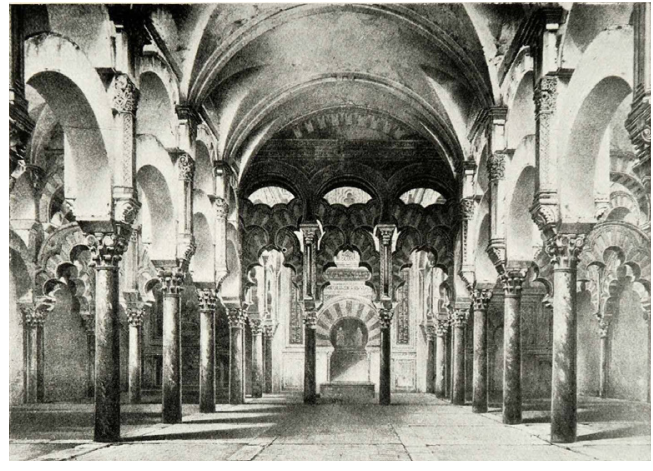

Fig. 14. La nave del mihrab a finales del siglo XIX, con las bóvedas todavía en su lugar. Fuente: José Amador de los Ríos y Rodrigo Amador de los Ríos y Villalta, Monumentos Latino-Bizantinos de Córdoba, volumen VII de Monumentos Arquitectónicos de España, 1879 (reproducido en una postal de 1907. Colección particular de Michele Lamprakos)

miembros de cada fe asistiendo al ritual del otro. Mientras tanto, el traslado todavía seguía discutiéndose entre bastidores, ahora como parte de un gran proyecto para convertir a Córdoba en una especie de ciudad-museo de la civilización 


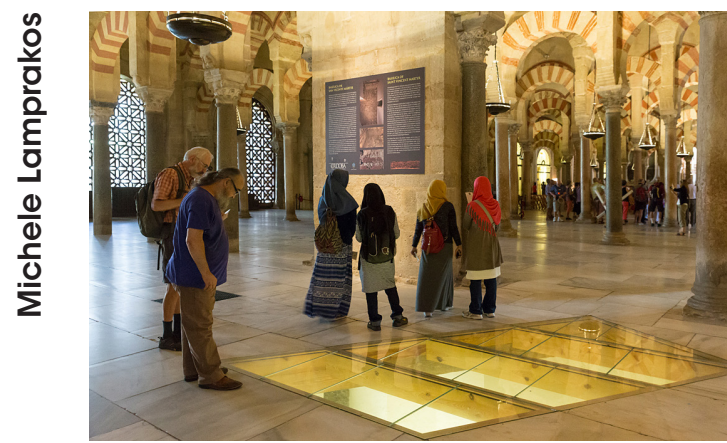

Fig. 15. Restos de un edificio que permanecen in situ, revelados al público en el año 2005. El panel explicativo sugiere que se trata de la Basílica de San Vicente, supuestamente demolida para dejar sitio a la mezquita, pero algunos académicos discrepan con esta interpretación

árabe-islámica. Financiada por los estados árabes y patrocinada por la UNESCO, la iniciativa finalmente murió, como muchos otros proyectos anteriores y posteriores que buscaron resaltar la herencia islámica de la ciudad.

En los años ochenta el proyecto ya centenario para re-islamizar la Mezquita se completó definitivamente gracias a la instalación de los últimos techos artesonados, con excepción de la zona este (la ampliación de al-Mansur), en la que se mantuvieron las bóvedas de yeso del siglo XVIII, conservando esa capa de la historia cristiana. En 1984 un plan de Rafael Moneo Vallés y Gabriel Ruiz Cabrero estableció nuevos criterios para la restauración. Haciéndose eco de las recomendaciones de la reunión de ICOMOS del año 1973, los arquitectos argumentaron que era necesario

aceptar la Mezquita de Córdoba tal y como ha llegado a nuestros días, asumiendo su compleja y rica historia. Su presente estado prueba la consistencia que la arquitectura de la primera mezquita tenía, capaz de asimilar tan numerosas y variadas intervenciones sin perder su integridad. ${ }^{30}$

Una nueva era había comenzado, ahora revirtiendo la larga empresa para recuperar el espacio islámico original. ${ }^{31}$ Aquel mismo año la Mezquita fue uno de los cinco monumentos agregados a la lista del Patrimonio Mundial. Ahora bien, el expediente de declaración, preparado por el nuevo gobierno regional andaluz y la Dirección General de Bellas Artes, no atribuía ningún valor a las capas cristianas. Más bien la "Mezquita de Córdoba", tal como se llamó al monumento, fue

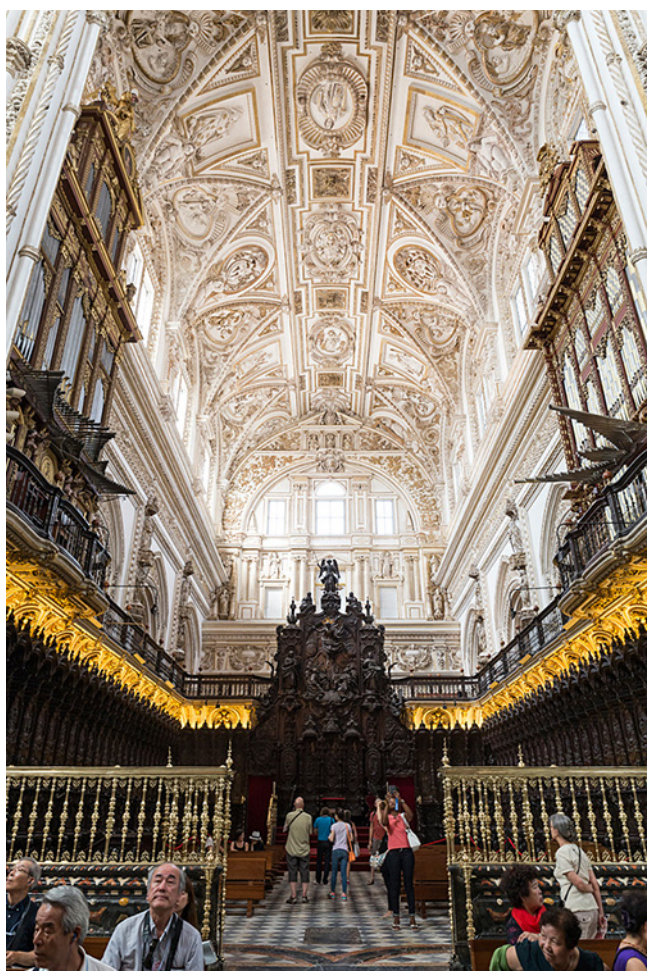

Fig. 16. El coro después de las obras de restauración

valorada exclusivamente por sus atributos como mezquita.

Cabría esperar que, con la transición a la democracia y la libertad de religión, habría una nueva apertura al pasado islámico en Córdoba. Pero de hecho ha ocurrido lo contrario. Hemos presenciado una nueva ola de "cristianización" en la Mezquita, ya que las autoridades de la Iglesia han tratado de minimizar, desacreditar e incluso negar el pasado islámico.

Solo podemos entender este fenómeno, una vez más, desde una perspectiva histórica. El final del régimen franquista reabrió una guerra cultural entre las fuerzas conservadoras católicas y las anticlericales, las que se habían visto obligadas a pasar a la clandestinidad después de la Guerra Civil. Una Iglesia cada vez más conservadora ha visto cómo sus privilegios y base social se han ido erosionando. La descentralización política ocurrida desde 1978 permitió a los gobiernos regionales escribir sus propias historias, lo que para Andalucía ha significado reivindicar y celebrar el 
pasado islámico, ${ }^{32}$ a menudo en oposición a la Iglesia. Mientras tanto, los verdaderos musulmanes comenzaron a regresar a la península, ahora como inmigrantes, turistas y conversos. Los conversos al Islam, no los inmigrantes, han intentado repetidamente lograr una autorización para orar en la Mezquita, incluso apelando al Vaticano. ${ }^{33}$ Los conversos españoles en particular ven el edificio como "su patrimonio", un patrimonio que, como el propio Islam, habría sido arrancado por la fuerza a sus antepasados.

En cuanto a la Mezquita, una vez más se convirtió en un campo de batalla con marcadas implicaciones simbólicas. A principios de la década de 1990, la Iglesia comenzó una campaña para eliminar la palabra «mezquita» en el nombre oficial del edificio. ${ }^{34}$ Unos años más tarde, al-Qaida emitió sus primeras amenazas de "retomar" alAndalus, afirmaciones que parecían terriblemente reales después de los atentados en los trenes en Madrid (2004). ${ }^{35}$ A lo largo de esa década, las autoridades de la Iglesia comenzaron a reescribir la historia del edificio a través de exhibiciones arqueológicas, folletos y una programación interpretativa que enfatizaban los "orígenes" cristianos del sitio y desacreditaban el legado islámico (fig. 15). ${ }^{36}$ Incluso se ha llegado a sugerir que la mezquita era un edificio derivado del helenismo tardío o bizantino, negando no solo la originalidad de la civilización hispano-islámica, sino su misma herencia cultural. ${ }^{37}$ Mientras tanto el crucero fue cuidadosamente restaurado. En cierto sentido, al revertir el proyecto de traslado, la restauración le ha otorgado un nuevo protagonismo al crucero: ahora luce más blanco y brillante gracias a la limpieza y el reemplazo de ventanas (fig. 16). Los arquitectos de la restauración argumentan que esto refleja con mayor precisión las intenciones de los arquitectos originales: el luminoso crucero no era meramente una ampliación, dicen, sino que más bien se pensó para transformar la naturaleza y el significado del edificio. ${ }^{38}$ La fábrica de la mezquita que lo rodea, ahora por contraste más oscura, ha sido crecientemente dedicada a exhibiciones museísticas pero despojada de significado espiritual, ya sea islámico o cristiano. Sin embargo, se han reintroducido algunos altares y estatuas, en los mismos lugares de los que habían sido eliminados, en este caso tan recientemente como en la década de 1980 (figs. 17 y 18).

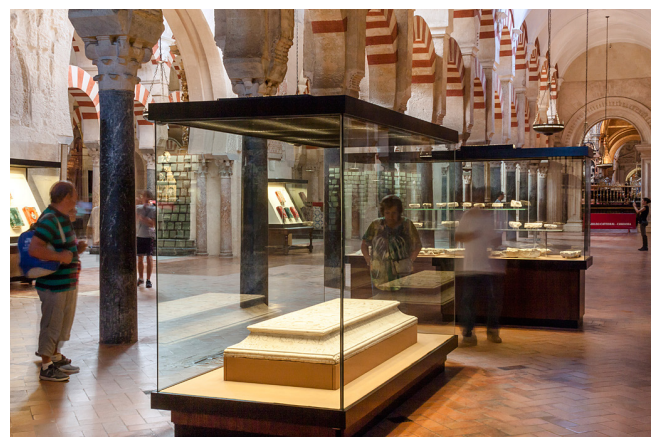

Fig. 17. Piezas exhibidas en el área de la ampliación de alMansur

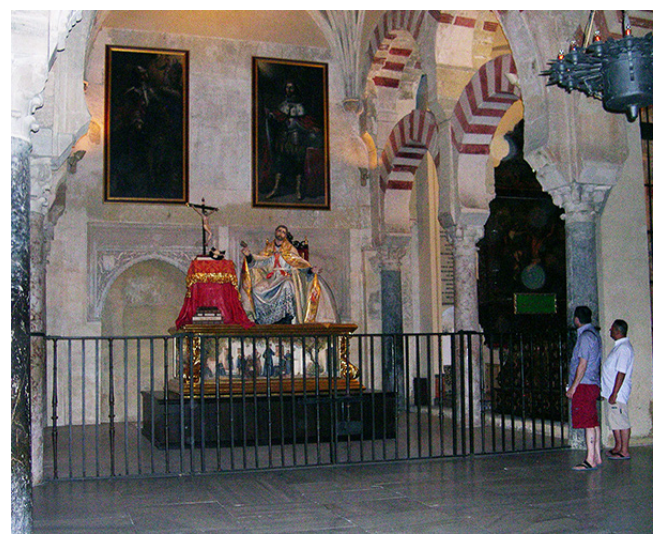

Fig. 18. Nueva capilla junto al muro de la qibla. El muro solo fue liberado de capillas en los años ochenta. Fotografía: Michele Lamprakos, 2014

En el año 2009 se produjo una tormenta política cuando se reveló que el obispo de Córdoba había registrado la Mezquita a su nombre tres años antes. Esto fue solo un caso, aunque muy simbólico, de los miles de propiedades registradas discretamente por las autoridades de la Iglesia bajo una ley de la era de Franco, que fue enmendada en 1998 para incluir lugares de culto. ${ }^{39}$ Los activistas ciudadanos contraatacaron, desafiando lo que vieron como otro intento de borrar la memoria histórica. A finales de 2013 lanzaron una petición internacional pidiendo a la UNESCO y al gobierno autonómico andaluz que hicieran valer el control público sobre la Mezquita, como monumento nacional y como sitio de Patrimonio Mundial. ${ }^{40}$ Su posición encontró el apoyo de un centenar de prominentes académicos de treinta y seis universidades en España y el extranjero, por medio de un manifiesto que criticó las políticas de 
la Iglesia y apoyó la propiedad pública. ${ }^{41}$ Los críticos señalaban que la Iglesia estaba recaudando enormes ingresos por la venta de entradas, pero no solo no pagaba impuestos sino que además recibía fondos públicos para proyectos de restauración y programación didáctica sin supervisión gubernamental, lo que le permitía "colonizar" el espacio y controlar la narrativa histórica. Las autoridades de la Iglesia no eran las únicas culpables ya que también las instituciones públicas parecían incapaces de actuar. ${ }^{42}$ No era la primera vez que los observadores esgrimían la defensa de la Mezquita por parte del Ayuntamiento en 1523 como ejemplo, la única ocasión en la historia, en que las autoridades civiles se habían enfrentado a la Iglesia. ${ }^{43}$

En la primavera de 2014 el ministro de Justicia, el conservador Alberto Ruiz-Gallardón, declaró en el Senado que la Mezquita pertenecía a la Iglesia. La UNESCO marcó una posición intermedia confirmando que el edificio era una catedral, un sitio religioso vivo, pero que mantenía el nombre de Mezquita, ya que el edificio había sido declarado Patrimonio de la Humanidad en 1984 por sus atributos como mezquita. La situación cambió con la formación de un gobierno municipal de izquierdas en 2015, cuando la nueva alcaldesa, Isabel Ambrosio, prometió devolver el título de propiedad al dominio público. La Iglesia acordó mantener la palabra mezquita en el nombre oficial del edificio, pero alegó que era el propietario histórico y legítimo. ${ }^{44}$ En 2017 se formó una comisión de expertos para estudiar la cuestión de la propiedad, dirigida por Federico Mayor Zaragoza, ex Director General de la UNESCO. El informe de la comisión, publicado en septiembre de 2018, desarrolla los fundamentos históricos en favor de la propiedad pública y aboga por una gestión conjunta del monumento. El informe tuvo repercusiones inmediatas en la prensa, provocando una predecible contraofensiva por parte de la Iglesia y sus partidarios. ${ }^{45}$ Sin embargo, este informe llegó en un momento muy delicado, ya que la indignación pública estaba en aumento por las inmatriculaciones de la Iglesia. Evaluar toda la legitimidad y revertir aquellas inmatriculaciones que eran ilegales se adivinaba como una tarea desalentadora para acudir a los tribunales. ${ }^{46} \mathrm{La}$ Mezquita se ha convertido en un punto crítico, una vez más, para batallas más importantes en el seno de la sociedad española. Sin embargo, en la discusión resulta notable la ausencia de una pregunta curiosa y fundamental: ¿por qué carecemos de información histórica básica sobre la Mezquita, cuando existe similar documentación para otros monumentos en otras ciudades?

\section{Arquitectura, memoria y futuro}

En las últimas décadas la convivencia se ha convertido en una especie de emblema, y también en la aspiración sincera de quienes ven a Córdoba como un modelo para una Europa multicultural. Sin embargo, la Mezquita también ha venido a complicar este mito así como ha desafiado muchos otros mitos y proyecciones. La campaña de la Iglesia para cambiar el nombre del edificio y desacreditar el legado islámico ha sido vergonzosa para algunos, resultando incongruente con la imagen de España como un estado europeo moderno. ${ }^{47}$ Una vez más, surgen preguntas no resueltas sobre el pasado, los contenidos suprimidos de un imaginario cultural, en torno a un círculo vicioso de maurofobia y maurofilia que tiene más que ver con las proyecciones de la propia identidad que con la realidad de lo musulmán. ${ }^{48}$

A lo largo de su vida la Mezquita ha sido un teatro donde se han puesto en escena y enfrentado las identidades. Pero también ha sido protagonista en ese drama. La Gran Mezquita proyectó el poder de los gobernantes omeyas y, a partir del siglo $\mathrm{X}$, su pretensión a regir el califato en todo el mundo mediterráneo. Después de la caída de Córdoba el edificio llegó a simbolizar la pérdida de al-Andalus, que sería lamentada durante siglos por los musulmanes. ${ }^{49}$ Para los cristianos fue apreciada como una maravilla arquitectónica y un trofeo. Pero a finales del siglo $X V$, en una época de construcción de catedrales y renovación de la lucha contra los musulmanes, la Mezquita debió ser vista por algunos miembros de la jerarquía de la Iglesia como una incómoda anomalía. Ubicada en un lugar destacado a orillas del río Guadalquivir, en lo que una vez fue una línea de combate en el frente de la Reconquista, ahora el corazón de un sitio declarado Patrimonio Mundial, la Mezquita sigue provocando preguntas que la cultura oficial ha ignorado o suprimido. Hoy, a pesar del generalizado interés internacional, pocos se 
han dado cuenta de que el conflicto vigente se refiere en última instancia a la arquitectura. La naturaleza dual del edificio evoca aquel viejo pero todavía potente debate sobre la identidad española y el legado del pasado islámico ¿Fue la época islámica, como algunos argumentan, simplemente un paréntesis en la historia de España? ¿Los españoles de hoy en día encarnan una esencia primordial, cristiano-europea, que sobrevivió milagrosamente, "no corrompida" por la cultura árabe-islámica? ¿O fue la época islámica algo fundamental para moldear la cultura y la identidad españolas? En otras palabras, ¿son los musulmanes "otros" o "nosotros"?

La lucha por la Mezquita ha polarizado a una comunidad y paralizado la investigación histórica. Es crucial establecer nuevos términos para el debate -un debate que se está siguiendo en todo el mundo - en un momento de creciente radicalización y polémica sobre el presunto "choque de ci- vilizaciones". A lo largo de su vida como catedral, y, más adelante, como monumento histórico, las intervenciones en el edificio son reveladoras acerca de cómo los contemporáneos vieron el pasado islámico: una élite, algo extraño, extranjero, amenazador, heroico, pacificador o exótico. Esas interpretaciones nos dicen algo acerca de cómo los contemporáneos se vieron a sí mismos, en relación con el otro real o imaginado. Las capas materiales de la Mezquita se han utilizado a veces para promover diversas prioridades ideológicas. Ahora bien, un estudio cuidadoso y riguroso de esas capas, aunque sean incompletas o reconstituidas, nos dirá todavía más -confundiendo las ideologías y complicando las respuestas fáciles. Las capas cuentan una historia compleja con múltiples actores, motivaciones e intereses que se han desarrollado en este espacio sublime: una historia que, a diferencia de los textos escritos, no se puede suprimir ni borrar por completo. 


\section{NOTAS}

* Traducción para la versión en castellano realizada por Jesús Ángel Sánchez García.

Agradezco a las muchas personas de Córdoba, Sevilla, Madrid y otros lugares que han compartido generosamente sus conocimientos, ideas y documentos; y a los editores de Quintana por su traducción y orientaciones. También quiero agradecer a las siguientes instituciones su asistencia y apoyo: la Facultad de Filosofía y Letras, la Universidad de Córdoba, y su biblioteca; el Cabildo y el Archivo Capitular de la Catedral de Córdoba; el Archivo Municipal, la Gerencia Municipal de Urbanismo, Diario CÓRDOBA, el Archivo Histórico Provincial, el Archivo del Museo Arqueológico y la Casa Árabe, todos en Córdoba; la Real Academia de Bellas Artes de San Fernando, Madrid; los Archivos de la UNESCO, París; y la Graduate School y la School of Architecture, Planning, and Preservation, University of MarylandCollege Park. A menos que se indique lo contrario, las fotografías fueron tomadas por Cornelia Steffens en 2015. Una primera versión de este artículo fue publicada en P. Karimi and N. Rabbat, eds., The Destruction of Culture Heritage in the Middle East: from Napoleon to ISIS, Aggregate Architectural Collaborative website, volume 3, December 2016: http://we-aggregate.org/piece/ memento-mauri-the-mosque-cathedral-of-cordoba

1 Salvador Muñoz Pérez, en la moción presentada al Ayuntamiento el 15 de enero de 1912. Citado en F.R. García Verdugo, "Los inicios del pensamiento conservacionista del casco histórico de Córdoba (1835-1958)," In Córdoba: Patrimonio Cultural de la Humanidad: una Aproximación Geográfica, ed. López Ontiveros y Naranjo Ramírez (Córdoba: Ayuntamiento de Córdoba, 1996), 131.

2 A los judíos se les dio a escoger en 1492 entre las opciones de la conversión o la expulsión. A los musulmanes se les ofreció una opción similar a lo largo del siglo XVI, aunque la aplicación real varió de unos lugares a otros. Los temores de asimilación incompleta de los "moriscos", como fueron llamados los musulmanes conversos, y su supuesta simpatía hacia los otomanos, llevaron a su expulsión final en 1609. Ver M. Carr, Blood and Faith: The Purging of Muslim Spain (New York and London: The New Press, 2009).

3 El "pacto de olvido" fue un acuerdo adoptado por los partidos políticos, tanto de derechas como de izquierdas, para abstenerse de enfrentamientos y sellar las disputas después de la muerte de Franco en 1975. Sobre el pacto de olvido como recuerdo, ver Javier Cercas, Anatomy of a Moment (New York: Bloomsbury, 2011), 91-93.

4 Las grandes mezquitas de Toledo, Jaén, Sevilla, Murcia, Granada y otras ciudades fueron usadas como catedrales durante variados períodos de tiempo, antes de que fueran demolidas y reemplazadas. Un proceso similar ocurrió con las pequeñas mezquitas de barrio que pasaron a ser usadas como iglesias parroquiales, y finalmente reemplazadas. Para una panorámica del proceso ver S. Calvo Capilla, "De mezquita a iglesia: el proceso de cristianización de los lugares de culto de al-Andalus," In P. Giráldez and M. Vendrell, eds., Trasformació, destrucció i restauració dels espais medievals (Barcelona: Patrimoni2.0 Consultors, 2016): 129-148; J. Kroesen, "From Mosques to Cathedrals: Converting Sacred Space during the Spanish Reconquista," Mediaevistik 21 (2008): 113-137; P. Buresi, "Les conversions d'églises et de mosquées en Espagne au Xle-XIlle siècles," In Religions et Sociétés au Moyen Âge: études offertes à Jean-Louis Biget par ses Anciens Élèves, réunies par P. Boucheron et J. Chiffoleau (Paris: Publications de la Sorbonne, 2000), 333-350; J. Harris, "Mosque to church conversions in the Spanish Reconquest," Medieval Encounters 3.2 (Leiden: Koninklijke Brill, 1997): 158-172; J. Orlandis, "Un problema eclesiástico de la reconquista española: la conversión de mezquitas en iglesias cristianas," Mélanges offerts à Jean Dauvillier (Toulouse: Centre d'histoire juridique méridionale, 1979), 595-604. Véase también Heather Ecker, "From Masjid to Casa-Mezquita: neighbourhood mosques in Seville after the Castilian conquest, 1248-1643" (PhD diss., Oxford University, 2000). Y en lo que respecta a la apropiación musulmana y ocasional demolición de iglesias, ver Buresi y también J. Dodds, Architecture and Ideology in Early Medieval Spain (University Park: Penn State Press, 1989), 60-66. Una tradición sostiene que la Gran Mezquita de Córdoba fue construida sobre las ruinas de una basilica visigoda que los musulmanes habrían compartido durante un tiempo con los cristianos, aunque las evidencias arqueológicas no son concluyentes. Para una reciente revisión historiográfica, ver F. Arce-Sainz, "La supuesta basílica de San Vicente en Córdoba: de mito histórico a obstinación historiográfica," AlQantara 36.1 (Janurary-February 2015): 11-44.

5 R. Moneo, "La Vida de los Edificios," Arquitectura 256 (SeptiembreOctubre 1985): 27-36; A. Capitel, "La Catedral de Córdoba: transformación cristiana de la Mezquita," Arquitectura 256 (Septiembre-Octubre 1985): 37-46. Un relato sobre las modificaciones se aporta en M. Nieto Cumplido, La Catedral de Córdoba (Córdoba: Obra Social y Cultural de CajaSur, 2007). Para los períodos tardío islámico y primeros tiempos de la dominación cristiana, ver H. Ecker, "The Great Mosque of Córdoba in the Twelfth and Thirteenth Centuries," Muqarnas 20 (2003): 113-141. Sobre el crucero como un reflejo de los nuevos gustos estéticos, ver A. Urquízar Herrera, "La memoria del pasado en la cristianización de la Mezquita de Córdoba durante la edad del Humanismo," In Correspondencia e Integración des Artes, $14^{\circ}$ Congreso Nacional de Hístoria del Arte, vol. 1, ed. I. Coloma Martín y J.A. Sánchez López, eds. (Málaga: Ministerio de Educación, Cultura, y Deportes/Dirección de Cooperación y Comunicación Cultural, 2003).

\section{H. Kamen, The Disinherited:}

The Exiles Who Created Spanish Culture (London and New York: Allen Lane/ Penguin Books, 2007), capítulo 2; y J.A. González Alcantud, Lo Moro: las lógicas de la derrota y la formación del esterotipo islamico (Rubí, Barcelona: Anthropos Editorial, 2002), capítulo 4.

719 naves con 33 huecos en cada nave. Robert Hillenbrand, "The use of spatial devices in the Great Mosque of Cordoba," Islâo e Arabismo na Peninsula Ibérica, Actas do XI Congreso da 
U.E.A.I. (Evora: Universidade, 1982), 184. El relato que sigue a continuación es deudor del análisis de Hillenbrand.

8 La literatura académica sobre la Mezquita es enorme. Ver S. Calvo Capilla, Las Mezquitas de al-Andalus (Almería: Fundación Ibn Tufayl de Estudios Arabes, 2014), 84-108; para unos sucintos análisis en inglés ver J. Dodds, "The Great Mosque of Cordoba," In AlAndalus: The Art of Islamic Spain (New York: Metropolitan Museum of Art, 1992), 11-26; y N. Khoury, "The Meaning of the Great Mosque of Cordoba in the Tenth Century," Muqarnas 13 (1996): 80-98. Las etapas en la evolución de la Mezquita fueron propuesta en su momento por Amador de los Rios en 1879. Para una visión más matizada ver Ecker, "The Great Mosque of Córdoba in the Twelfth and Thirteenth Centuries," 113-115.

9 Entre los posibles precedentes para esa forma se incluyen salas de recepción reales de Madinat al-Zahra, y también iglesias mozárabes en el norte de España (J. Dodds, Architecture and Ideology, 94-106; S. Calvo Capilla, Las Mezquitas de al-Andalus, 87). Dodds relaciona la ampliación de al-Hakam con el simbolismo y ritual cristianos. Sobre este asunto ver también O. Grabar, "Notes sur le mihrab de la Grande Mosquée de Cordoue," In Le Mihrab dans I'Architecture et la Religion Musulmane, ed. A. Papadopoulo (Leiden: E. J. Brill, 1988), 115-122; y Robert Hillenbrand, "'The Ornament of the World': Medieval Cordoba as Cultural Centre," In The Legacy of Muslim Spain, ed. S. K. Jayyusi and M. Marín (Leiden; New York: E.J. Brill, 1992), 134-135.

${ }^{10}$ La mezquita ya se había convertido en iglesia en una ocasión anterior, en 1146, cuando las fuerzas castellanas tomaron brevemente la ciudad y la dedicaron a la Santa Cruz de Jerusalem. Cuando los musulmanes retomaron Córdoba, la volvieron a convertir en mezquita. Ver Ecker, "The Great Mosque of Córdoba in the Twelfth and Thirteenth Centuries," 116-117; Nieto Cumplido, La Catedral de Córdoba, 329-338. Cuando las mezquitas fueron reutilizadas como iglesias, normalmente se dedicaron a la Virgen María, la patrona de la Reconquista (J. Kroesen, "From
Mosques to Cathedrals," 115; J. Harris, "Mosque to church conversions," 165).

11 Ecker, "The Great Mosque of Córdoba," 120-121, apoyándose en el análisis de Khoury ("The Meaning of the Great Mosque," 89). Ecker supone que fue la proximidad del sabat, un puente cubierto hacia el viejo palacio califal -hoy episcopal- lo que determinó la ubicación de la capilla mayor.

12 M. Muñoz Vázquez, "Vicisitudes de la Mezquita-Catedral de Córdoba," In La Mezquita de Córdoba: empeño universal (Córdoba, 1973), 50; I. Sanz Sancho, Geografía del Obispado de Córdoba en la Baja Edad Media (Madrid, 1995), 58. Nieto Cumplido y otros creen que la iglesia fue consagrada bajo la cúpula del vestíbulo de al-Hakam, basándose en una inscripción parcial del año 1236 que sobrevive en dicha cúpula. Ver Nieto Cumplido, La Catedral de Córdoba, 449-450; y Corpus Mediaevale Cordubense (Córdoba: Monte de Piedad y Caja de Ahorros de Córdoba, 1979), 1: 87, doc. 162.

${ }_{13}$ Esta iglesia parroquial o sagrario fue desplazada a la esquina sudoeste del edificio en el año 1586, cuando el crucero estaba en construcción. El término sagrario se refiere al lugar donde se guarda la hostia, y también a la capiIla interior en algunas catedrales que sirve de iglesia para la cercana parroquia.

14 Ver, por ejemplo, la comparación de Antonio Almagro entre los destinos de la mezquita de Córdoba y la del Viernes de Sevilla: "De Mezquita a catedral: una transformación imposible," In La Piedra Postrera: V Centenario de la conclusión de la Catedral de Sevilla, vol. 1, ed. A. Jiménez Martín (Seville: Cabildo Metropolitano, 2007), 13-47.

15 Descriptio Cordovbae, escrito hacia 1450 por "Jerónimo", posiblemente un canónigo en el Real Colegio de San Hipólito de Córdoba. El texto ha sido parcialmente transcrito del original en latín por M. Nieto Cumplido en La Catedral de Córdoba, 319-320. En la primera transcripción Nieto escribió "antiguos bárbaros" en lugar de "antiguos poseedores" (Córdoba en el Siglo XIV, Córdoba: Tip. Católica-Ing. Torres Quevedo, 1973, 67-8).

16 Mudéjar se refiere a los musulmanes viviendo bajo el dominio Cris- tiano, y también a las artes islámicas producidas en esas zonas cristianas y para los patronos cristianos, musulmanes y judíos. Sobre la Capilla Real ver M.A. Jordano Barbudo, El Mudéjar en Córdoba (Córdoba: Diputación Provincial, 2002), 117-129; y La Sinagoga de Córdoba y las yeserías mudéjares en la Baja Edad Media (Córdoba: Servicio de Publicaciones Universidad de Córdoba, 2011), 139-161.

17 L. Torres Balbás, La Mezquita de Córdoba y las Ruinas de Medinat al-Zahra (Madrid: Editorial Plus-Ultra, 1952), 105-106. Esta intervención dio forma al área que durante dos siglos y medio había acogido el coro del cabildo obispal.

18 J. Harvey, The Cathedrals of Spain (London: B. T. Batsford, Ltd., 1957), 58, 223.

19 Según lo recogido por Juan Gómez Bravo, canónigo de Córdoba en 1739 (Catálogo de los obispos de Córdoba, y breve noticia histórica de su iglesia catedral, y obispado, 1778 edition, vol. 1, 419-420).

20 Libro de Actas Capitulares, 29 de abril de 1523, Archivo Municipal de Córdoba, C-2122/43. Una real provisión fechada el 14 de julio de 1523 sugiere que la audiencia de apelación real había fallado a favor de la ciudad y suspendido las obras, al menos por un tiempo. Ver M.A. Ortí Belmonte, "Oposición del cabildo municipal de Córdoba a la construcción del crucero de la Mezquita," Boletín de la Real Academia de Córdoba, año XXV, no. 70 (enero-junio): 271-277.

21 G. Ruiz Cabrero, Dibujos de la Catedral de Córdoba: Visiones de la Mezquita (Barcelona: Cabildo Catedral de Córdoba/This Side Up, 2009), 49. Para un análisis sobre la intervención de Hernán Ruiz I ver A. Capitel, "La Catedral de Córdoba"; J. Lorda Iñarra y M.A. Martínez Rodríguez, "El primer proyecto de Hernán Ruiz para la Catedral de Córdoba," In Actas del Séptimo Congreso Nacional de Historia de la Construcción, Santiago 26-29 octubre 2011, ed. S. Huerta et al. (Madrid: Istituto Juan de Herrera, 2011), 791-798. Para tener una idea general sobre el proceso de construcción ver M. Nieto Cumplido, La Catedral de Córdoba, 503-525. 
22 J. Aranda Doncel, "La mezquita de Córdoba a través de los viajeros extranjeros de los siglos XVII y XVIII," In Homenaje a Manuel Ocaña Jiménez (Córdoba: Imprenta San Pablo, 1990), 35-36.

${ }^{23}$ Felipe III firmó el edicto de expulsión en el año 1609. En torno al debate que condujo al decreto, ver Carr, Blood and Faith, capítulo 17.

${ }^{24}$ Las bóvedas permanecen en su lugar en la parte oriental del edificio. El arquitecto encargado de la restauración, Gabriel Ruiz Cabrero, razonó sobre su preservación en la década de los ochenta.

${ }^{25}$ La fachada este fue uno de los numerosos proyectos dirigidos en los primeros años del siglo XX por Ricardo Velázquez Bosco, el primer arquitecto estatal encargado de los trabajos de restauración. Ver G. Ruiz Cabrero, "Dieciséis proyectos de Ricardo Velázquez Bosco. La Mezquita-Catedral de Córdoba," Arquitectura 256 (1985): 47-56.; y S. Herrero, De lo original a lo auténtico. La restauración de la Mezquita Catedral de Córdoba durante el siglo XX (Córdoba: Cabildo Catedral de Córdoba, 2017), capítulo 1.

${ }^{26}$ El término "re-islamicization" se ha tomado de Ecker.

27 Sobre el "Moro" como rebelde, ver H. Kamen, The Disinherited, 72.

28 En el año 1972, en medio de un nuevo intento para trasladar el crucero, el historiador del arte marqués de Lozoya (Juan de Contreras y López de Ayala) escribió: "Hace más de treinta años, siendo yo director general de Bellas Artes [1939-1951], surgió la idea, en un impulso de gratitud al mundo islámico, que tan eficazmente había contribuido a la victoria, de desmontar y trasladar la catedral gótico-renacentista de Córdoba para restituir la Mezquita a su integridad estilística y a su antiguo destino, para que fuese, como lo fue en el siglo $X$, centro espiritual del Islam. Me opuse entonces, en cuanto me fue posible, y tuve la fortuna de ser escuchado" ("La islamización de la Mezquita no remediaría nada," Diario Ya, Noviembre 7, 1972).

${ }^{29}$ Dos narraciones diferentes sobre estos hechos se encuentran en Nieto Cumplido, La Mezquita de Córdoba y el
ICOMOS (Córdoba: Servicio de Publicaciones del Excmo. Ayuntamiento, 1976); y J.I. Cassar Pinazo, "Anotaciones al artículo 'Datos para la restauración de la Mezquita de Córdoba,' Rafael Castejón y Martínez de Arizala," Papeles de Partal: Restauración Monumental 2 (November 2004): 17-44. Para otros análisis recientes sobre la polémica del traslado ver F. Daroca Bruño, "Córdoba 1950, Rafael de La-Hoz como motor de la modernidad." (PhD thesis, Universidad de Sevilla, July 2017): 136-153; S. Herrero, De lo original a lo auténtico, 223-233; y M. Lamprakos, "Recovering the Great Mosque of Cordoba: the History of an Idea" (próxima publicación, 2019).

30 R. Moneo Vallés y G. Ruiz Cabrero, "Proyecto de restauración de la Mezquita-Catedral de Córdoba," 1984, citado en S. Herrero, De lo original a lo auténtico, 257.

31 S. Herrero, De lo original a lo auténtico, 245.

${ }^{32}$ Ver M. Díaz-Andreu, "Islamic Archeology and the Origin of the Spanish Nation," In Nationalism and Archeology in Europe: an Introduction, ed. M. DíazAndreu and T. Champion (London: UCL Press, 1996), 86.

33 Estos intentos vienen de comienzos de los años ochenta. Ver J. Roberson, "From Dictatorship to Democracy: Cordoba's Islamic Monuments in the Twentieth Century," In Rethinking Place in South Asian and Islamic Art, 1500-Present, Rebecca R. Brown and Deborah S. Hutton, eds. (Abingdon and New York: Routledge, 2017), 128-130.

34 En una sesión plenaria en el año 1994, el Ayuntamiento de Córdoba aprobó el nombre mixto de "Mezquita-Catedral", según entrevista con el alcalde Herminio Trigo (1986-1995), en junio de 2018. Cuando la lista del Patrimonio Mundial fue ampliada en 1994 para incluir el entorno circundante, la cuestión del nombre del edificio fue dejada a un lado; así, por sugerencia del delegado español, el lugar fue simplemente llamado "Centro Histórico de Córdoba" (UNESCO Archives, Paris, CLTMHC/NOM 135).

$35 \mathrm{H}$. Aidi, "The Interference of al-Andalus: Spain, Islam, and the West," Social Text 87, 24:2 (Summer 2006): 81-84.
36 Por ejemplo, la exhibición de los supuestos restos de la Basílica de San Vicente bajo el suelo de la mezquita. Ver nota 4 y figura 15 .

37 Ver la introducción de Nieto Cumplido a la edición de 2007 de La Catedral de Córdoba, 13-20; y su reciente libro La Mezquita de Córdoba, Joya Bizantina (Córdoba: Cabildo de la Santa Iglesia de Córdoba, 2016). El obispo de Córdoba Demetrio Fernández apoya esta tesis: "Bueno, en realidad, los Omeyas, los califas, no tenían arquitectos propios, ni crearon un arte nuevo, no es arte musulmán. Fueron a por sus paisanos cristianos de DamasCO, y los trajeron a Córdoba. Pero el arte no es musulmán, es bizantino... Es cristiano bizantino. Los moros (sic) solo pusieron el dinero" (Entrevista al Obispo Demetrio Fernández en Revista 17: un análisis del estado de cultura en Córdoba, Diciembre 2016, 107). En la misma entrevista el Obispo negó que las autoridades de la Iglesia hubieran intentando eliminar la palabra "mezquita" en el nombre del edificio, aunque él mismo lo hubiera defendido; ver "La Catedral de Córdoba." $A B C$ Córdoba, Octubre 10, 2010, 48.

Los intentos de la Iglesia para desacreditar e incluso negar el pasado Islámico de la Mezquita son parte de un más amplio debate, recientemente renovado, sobre el legado del Islam en la península Ibérica, en realidad un debate que se remonta al siglo XIX. Sobre este asunto ver A. García Sanjuán, "Rejecting al-Andalus, exalting the Reconquista: historical memory in contemporary Spain," Journal of Medieval Iberian Studies 10:1, 2018, 127-145; y La conquista islámica de la Península Ibérica y la tergiversación del pasado: del catastrofismo al negacionismo, Madrid: Marcial Pons, 2013.

38 G. Rebollo, G. Ruiz Cabrero, y S. Herrero, "La Catedral es una catedral (II)," ABC Seville, Septiembre 23, 2013 [accessed October 17, 2018] http:// sevilla.abc.es/cordoba/20130922/ sevp-catedral-catedral-20130922.html. Acerca de la restauración del crucero ver S. Herrero, De lo original a lo auténtico, 285-8; y G. Rebollo Puig y G. Ruiz Cabrero, "El crucero 'restolado'," Patrimonio Cultural de España, 2010, no. 4, 151-163. 
39 La Ley Hipotecaria de 1946 permitió a los representantes de la Iglesia registrar edificios, tierras e incluso espacios públicos como propiedad privada, pero no lugares de culto. La ley fue modificada en 1998, bajo el gobierno de Aznar, para permitir el registro de lugares de culto. Los edificios fueron frecuentemente registrados sin pruebas de propiedad, y sin el conocimiento de las autoridades civiles. Aunque este privilegio finalizó en 2015, la medida no se ha hecho retroactiva. Ver "Clarificar la Propriedad," El País, Septiembre 10, 2018 [accessed 17 October, 2018] https://elpais.com/elpais/2018/09/10/ opinion/1536605389_931290.html

$40 \quad$ https://www.change.org/p/ salvemos-la-mezquita-de-córdoba-poruna-mezquita-catedral-de-todos

La petición fue promovida por la Plataforma Mezquita-Catedral de Córdoba: Patrimonio de tod@s, establecida en 2013. Como contexto de la disputa ver especialmente E. Calderwood, "The Reconquista of the Mosque of Cordoba," Foreign Policy, April 10, 2015; y B. Jover Báez y B. Rosa, "Patrimonio cultural en disputa: la Mezquita-Catedral de Córdoba," Cuadernos Geográficos 56:1, 2017, 322-343.

41 "Cien expertos critican la situación de la Mezquita de Córdoba," El País, Noviembre 3, 2015 [accessed October 11, 2018] https:// elpais.com/politica/2015/11/03/actualidad/1446553126_305752.html

Ver también la aportación de opinión de Eduardo Manzano, "El Affaire de la Mezquita de Córdoba," El País, Abril 13, 2015 [accessed October 11, 2018] https://elpais.com/elpais/2015/02/05/ opinion/1423137778_840752.html

42 Por ejemplo, los guías turísticos son aprobados por la Iglesia y solo pueden introducir grupos en la Mezquita después de pasar un test especial, para asegurar su adhesión a la narrativa autorizada.

43 En un acto público en 1921, Antonio Jaén Morente, historiador, abogado y político republicano afirmó: "Generalmente, nadie se ha preocupado del patrimonio artístico, y ni siquiera tuvo eco la voz de algún docto o de al- gún enamorado del Arte de Córdoba. Sólo una vez, allá en los albores del siglo XVI, cuando el Cabildo Catedral, llevado de un equivocado propósito, se construye una catedral cristiana, pero despedazando previamente la mora mezquita, se alza un poco altiva la voz del Ayuntamiento, que intenta oponerse al desafuero, y siempre serán honra y preclaro don suyo las frases de su pregón: 'mandamos que ningún albañil, ni cantero, ni carpintero, ni peón, no sean osados de tocar en la dicha obra, so pena de muerte'.... Después, nada" (A. Jaén Morente, "El problema artístico de la Ciudad de Córdoba." Conferencia pronunciada en el Círculo Mercantil por iniciativa de la Junta de Defensa y Progreso, 10 Diciembre 1921, Córdoba: Imprenta Moderna, 1922, pp. 8-9).

44 Ver "The Mosque in the Cathedral," The Economist, October 8, 2015 [accessed October 11, 2018] https://www.economist.com/ europe/2015/10/08/the-mosque-inthe-cathedral; "El Cabildo insta a resolver por vía jurídica la titularidad de la mezquita," El País, Marzo 21, 2016 [accessed October 11, 2018] https:// elpais.com/ccaa/2016/03/31/andalucia/1459439248_383505.html

4543 académicos, en su mayoría especialistas en historia medieval, firmaron un documento desestimando el informe de la comisión: "Mas de 40 historiadores se rebelan contra el informe del Consistorio sobre la Mezquita-Catedral de Córdoba," $A B C$ Córdoba, Septiembre 23, 2018 [accessed 17 October 2018] https://sevilla.abc.es/andalucia/ cordoba/sevi-cuarenta-medievalistasdenuncian-informe-mezquita-cordobacarece-minimo-rigor-201809221052 noticia.html. Rafael Sánchez Saus, catedrático de Historia Medieval de la Universidad de Cádiz, conocido por sus posiciones políticas de ultraderecha, fue el impulsor real tras el documento. Entre los firmantes está Serafín Fanjul, principal representante de las posiciones ultraconservadoras en la historiografía contemporánea española sobre al-Andalus.

Alejandro García Sanjuán, profesor de Historia Medieval en la Uni- versidad de Huelva y miembro de la comisión de expertos, respondió a los intentos por desacreditar el informe de la comisión, profundizando en los argumentos históricos contra la propiedad de la Iglesia. Sus razones se basan dos puntos principales: primero, no hay evidencia documental de que Fernando III diera la Mezquita a la Iglesia; y, segundo, era norma para las mezquitas apropiadas permanecer como propiedad del Rey, el cual podía disponer de ellas como quisiera. La norma está documentada en las Siete Partidas, código legal desde los tiempos de Alfonso X, hijo y sucesor de Fernando III. Ver A. García Sanjuán, "La propiedad de la Mezquita de Córdoba: una historia tergiversada" https://www.eldiario.es/andalucia/ enabierto/propiedad-Mezquita-Cordoba-historia-tergiversada_6_816528342. html; y del mismo, "¿Donó Fernando III la Mezquita de Córdoba a la Iglesia en 1236?," Al-Andalus y la Historia, Septiembre 26, 2018, http://www . alandalusylahistoria.com/?p=580

${ }^{46}$ Al tiempo de escribirse este texto, el gobierno del PSOE estaba preparando para su difusión una lista de las propiedades registradas por la Iglesia, según el compromiso afirmado cuando estaba en la oposición ("Clarificar la propiedad," El País, Septiembre 10, 2018).

47 Sobre la verguenza como un ingrediente de la identidad nacional ver M. Herzfeld, Cultural Intimacy: Social Poetics of the Nation State (New York: Routledge, 2005), 3-6.

48 Ver J.A. González Alcantud, El mito de al Andalus: Orígenes y actualidad de un ideal cultural (Editorial Almuzara, 2014), capítulo 2. En cuanto al papel de la morofobia en el conflicto actual, ver Calderwood, "The Reconquista of the Mosque of Cordoba."

49 N. Khoury, "The Meaning of the Great Mosque of Cordoba in the Tenth Century," 80. 


\section{REFERENCIAS}

Aidi, Hishaam. 2006. "The Interference of alAndalus: Spain, Islam, and the West." Social Text 87, vol. 24, no. 2 (Summer): 67-88.

Almagro Gorbea, Antonio. 2007. "De mezquita a catedral: una adaptación impossible." In La Piedra Postrera: V Centenario de la conclusión de la Catedral de Sevilla, vol. 1, edited by Alfonso Jiménez Martín, 13-47. Sevilla: Cabildo Metropolitano.

Aranda Doncel, Juan. 1990. "La mezquita de Córdoba a través de los viajeros extranjeros de los siglos XVII y XVIII." In Homenaje a Manuel Ocaña Jiménez, 35-36. Córdoba: Imprenta San Pablo.

Arce-Sainz, Fernando. 2015. "La supuesta basílica de San Vicente en Córdoba: de mito histórico a obstinación historiográfica." AlQantara 36, no. 1 (January-June): 11-44

Buresi, Pascal. 2000. "Les conversions d'églises et de mosquées en Espagne au Xle-XIlle siècles." In Religions et Sociétés au Moyen Âge: Études offertes à Jean-Louis Biget par ses Anciens Élèves, réunies par Patrick Boucheron et Jacques Chiffoleau, 333-350. Paris: Publications de la Sorbonne.

Calvo Capilla, Susana. 2014. Las Mezquitas de al-Andalus. Almería: Fundación Ibn Tufayl de Estudios Arabes

Calvo Capilla, Susana. 2016. "De mezquita a iglesia: el proceso de cristinización de los lugares de culto de al-Andalus." In Trasformació, destrucció i restauració dels espais medievals, edited by Pilar Giráldez and Màrius Vendrell, 129-148. Barcelona: Patrimoni2.0 Consultors.

Capitel, Antón. 1985. "La Catedral de Cordoba: transformación cristiana de la Mezquita."

Arquitectura 256 (septiembre-octubre 1985): 37-46.

Carr, Matthew. 2009. Blood and Faith: The Purging of Muslim Spain. New York and London: The New Press

Cassar Pinazo, José Ignacio. 2004. "Annotaciones al artículo 'Datos para la restauración de la Mezquita de Cordoba,' Rafael Castejón y Mar- tinez de Arizala." Papales de Partal, Restauración Monumental, no. 2 (November): 17-44.

Cercas, Javier. 2011. Anatomy of a Moment. New York: Bloomsbury.

Daroca Bruño, Francisco. 2017. "Córdoba 1950, Rafael de La-Hoz como motor de la modernidad." PhD thesis, Universidad de Sevilla.

Díaz-Andreu, Margarita. 1996. "Islamic Archaeology and the Origin of the Spanish Nation." In Nationalism and Archaeology in Europe: an Introduction, edited by Margarita Díaz-Andreu and Timothy Champion, 66-89. London: UCL Press.

Dodds, Jerrilynn. 1989. Architecture and Ideology in Early Medieval Spain. University Park: Penn State University Press.

Dodds, Jerrilynn. 1992. "The Great Mosque of Cordoba." In Al-Andalus: The Art of Islamic Spain, edited by Jerrilynn Dodds, 11-26. New York: Metropolitan Museum of Art.

Ecker, Heather. 2000. "From Masjid to CasaMezquita: neighbourhood mosques in Seville after the Castilian conquest, 1248-1643." PhD diss., Oxford University.

Ecker, Heather. 2003. "The Great Mosque of Córdoba in the Twelfth and Thirteenth Centuries." Muqarnas 20: 113-141.

García Sanjuán, Alejandro. 2013. La conquista islámica de la Península Ibérica y la tergiversación del pasado: del catastrofismo al negacionismo. Madrid: Marcial Pons.

García Sanjuán, Alejandro. 2018. "Rejecting alAndalus, exalting the Reconquista: historical memory in contemporary Spain." Journal of Medieval Iberian Studies 10:1, 127-145

García Verdugo, Francisco R. 1996. "Los inicios del pensamiento conservacionista del casco histórico de Córdoba (1835-1958)." In Córdoba: Patrimonio Cultural de la Humanidad: una Aproximación Geográfica, edited by Antonio López Ontiveros and José Naranjo Ramírez, 119-148. Córdoba: Ayuntamiento de Córdoba, Gerencia de Urbanismo

Gómez Bravo, Juan. 1778. Catálogo de los obispos de Córdoba, y breve noticia histórica de su 
iglesia catedral, y obispado, vol. 1. Córdoba: J. Rodríguez.

González Alcantud, José Antonio. 2002. Lo Moro: las lógicas de la derrota y la formación del esterotipo islámico. Rubí, Barcelona: Anthropos Editorial.

González Alcantud, José Antonio. 2014. El mito de al Andalus: Orígenes y actualidad de un ideal cultural. Editorial Almuzara.

Grabar, Oleg. 1998. "Notes sur le mihrab de la Grande Mosquée de Cordoue." In Le Mihrab dans l'Architecture et la Religion Musulmane, edited by Alexandre Papadopoulo, 115-122. Leiden and New York: E. J. Brill.

Harvey, John. 1957. The Cathedrals of Spain. London: B. T. Batsford, Ltd.

Herrero, Sebastián. 2018. De lo original a lo auténtico. La restauración de la Mezquita Catedral de Córdoba durante el siglo XX. Córdoba: Cabildo Catedral de Córdoba.

Herzfeld, Michael. 2005. Cultural Intimacy: Social Poetics of the Nation State. New York: Routledge.

Hillenbrand, Robert. 1982. "The use of spatial devices in the Great Mosque of Cordoba." In Islâo e Arabismo na Peninsula Ibérica, Actas do XI Congreso da U.E.A.I., 181-193. Evora: Universidade.

Hillenbrand, Robert. 1992. "The Ornament of the World': Medieval Cordoba as Cultural Centre." In The Legacy of Muslim Spain, edited by Salma Khadra Jayyusi (chief consultant to the editor Manuela Marín), 112-135. Leiden and New York: E.J. Brill.

Jaén Morente, Antonio. 1922. “El problema artística de la Ciudad de Córdoba." Conferencia pronunciada en el Círculo Mercantil por iniciativa de la Junta de Defensa y Progreso, 10 Diciembre 1921. Córdoba: Imprenta Moderna.

Jordano Barbudo, María Ángeles. 2002. El mudéjar en Córdoba. Córdoba: Diputación Provincial.

Jordano Barbudo, María Ángeles. 2011. La Sinagoga de Córdoba y las yeserías mudéjares en la Baja Edad Media. Córdoba: Servicio de Publicaciones Universidad de Córdoba.
Kamen, Henry. 2007. The Disinherited: The Exiles Who Created Spanish Culture. London and New York: Allen Lane/Penguin Books.

Khoury, Nuha. 1996. "The Meaning of the Great Mosque of Cordoba in the Tenth Century." Muqarnas 13, 80-98

Kroesen, Justin E. A. 2008. "From Mosques to Cathedrals: Converting Sacred Space during the Spanish Reconquista." Mediaevistik 21, no. 1: 113-137. https://doi. org/10.3726/83010_113

Lorda Iñarra, Joaquín, and María Angélica Martínez Rodríguez. 2011. "El primer proyecto de Hernán Ruiz para la Catedral de Córdoba." In Actas del Séptimo Congreso Nacional de Historia de la Construcción, Santiago 26-29 octubre 2011, edited by S. Huerta et al., 791798. Madrid: Instituto Juan de Herrera.

Moneo Vallés, Rafael. 1985. "La Vida de los Edificios." Arquitectura 256 (septiembre-octubre 1985): 27-36.

Muñoz Vázquez, Miguel. 1973. "Vicisitudes de la Mezquita-Catedral de Córdoba." In La Mezquita de Córdoba: empeño universal, 49-53. Córdoba: Servicio de Publicaciones del Excmo Ayuntamiento de Córdoba.

Nieto Cumplido, Manuel. 1973. Córdoba en el Siglo XIV. Córdoba: Tip. Católica-Ing. Torres Quevedo.

Nieto Cumplido, Manuel. 1976. La Mezquita de Córdoba y el ICOMOS. Córdoba: Servicio de Publicaciones del Excmo. Ayuntamiento.

Nieto Cumplido, Manuel. 1979. Corpus Mediaevale Cordubense, vol. 1. Córdoba: Monte de Piedad y Caja de Ahorros de Córdoba.

Nieto Cumplido, Manuel. 2007. La Catedral de Córdoba. Córdoba: Publicaciones Obra Social y Cultural de CajaSur.

Nieto Cumplido, Manuel. 2016. La Mezquita de Córdoba, Joya Bizantina. Córdoba: Cabildo de la Santa Iglesia de Córdoba.

Orlandis, José. 1979. “Un problema eclesiástico de la reconquista española: la conversión de mezquitas en iglesias cristianas." In Mélanges offerts à Jean Dauvillier, 595-604. Toulouse: Centre d'histoire juridique méridionale. 
Ortí Belmonte, Miguel Ángel. 1954. "Oposición del cabildo municipal de Córdoba a la construcción del crucero de la Mezquita." Boletín de la Real Academia de Córdoba, año XXV, no. 70 (enero-junio): 271-277.

Rebollo Puig, Gabriel, and Gabriel Ruiz Cabrero. 2010. "El crucero restolado." Patrimonio Cultural de España 4, 151-163.

Roberson, Jennifer. 2017. "From Dictatorship to Democracy: Cordoba's Islamic Monuments in the Twentieth Century." In Rethinking Place in South Asian and Islamic Art, 1500-Present, edited by Deborah S. Hutton and Rebecca R. Brown, 116-136. Abingdon and New York: Routledge, 2017.

Ruiz Cabrero, Gabriel. 1985. “Dieciséis proyectos de Ricardo Velázquez Bosco. La Mezquita-Catedral de Córdoba." Arquitectura 256 (septiembre-octubre 1985): 47-56.

Ruiz Cabrero, Gabriel. 2009. Dibujos de la Catedral de Córdoba: Visiones de la Mezquita. Barcelona: Cabildo Catedral de Córdoba/This Side Up.

Sanz Sancho, Iluminado. 1995. Geografía del Obispado de Córdoba en la Baja Edad Media. Madrid: Ediciones Polifemo.

Torres Balbás, Leopoldo. 1952. La Mezquita de Córdoba y las Ruinas de Medinat al-Zahra. Madrid: Editorial Plus-Ultra.

Urquízar Herrera, Antonio. 2002. “La memoria del pasado en la cristianización de la Mezquita de Córdoba durante la edad del Humanismo." In Correspondencia e Integración de las Artes, $14^{\circ}$ Congreso Nacional de Historia del Arte, edited by Isidro Coloma Martín and Juan Antonio Sánchez López. Málaga: Ministerio de Educación, Cultura, y Deportes/Dirección de Cooperación y Comunicación Cultural.

\section{Prensa}

"Clarificar la Propiedad" (editorial). El País, Septiembre 10, 2018. https:// elpais.com/elpais/2018/09/10/opinion/1536605389_931290.html

Contreras y López de Ayala, Juan (el Marqués de Lozoya). 1972. "La islamización de la Mezqui- ta no remediaría nada." Diario Ya, Noviembre 7, 1972.

Donadio, Rachel. 2010. "Name Debate Echoes Old Clash of Faiths." New York Times, October 4, 2010. https://www.nytimes. com/2010/11/05/world/europe/05cordoba. html

Fernández, Demetrio. 2010. "La Catedral de Córdoba." ABC Córdoba, Octubre 10, 2010.

Fernández, Demetrio. 2016. Entrevista (por Jon Sistiaga), Revista 17. Un análisis del estado de cultura en Córdoba, Diciembre 2016, 102107.

García Sanjuán, Alejandro. 2018. “La propiedad de la Mezquita de Córdoba: una historia tergiversada." eldiario.es Andalucía, Septiembre 20, 2018. https://www.eldiario.es/andalucia/ enabierto/propiedad-Mezquita-Cordoba-historia-tergiversada_6_816528342.html

García Sanjuán, Alejandro. 2018. “¿Donó Fernando III la Mezquita de Córdoba a la Iglesia en 1236?" Al-Andalus y la Historia, Septiembre 26, 2018. http://www.alandalusylahistoria.com/?p=580

López, Baltasar. 2018. "Más de 40 historiadores se rebelan contra el informe del Consistorio sobre la Mezquita-Catedral de Córdoba." ABC Córdoba, Septiembre 23, 2018. https://sevilla. abc.es/andalucia/cordoba/sevi-cuarenta-medievalistas-denuncian-informe-mezquita-cordoba-carece-minimo-rigor-201809221052_ noticia.html

Lucas, Ángeles. 2016. "El Cabildo insta a resolver por vía jurídica la titularidad de la mezquita." El País, Marzo 21, 2016. https://elpais.com/ccaa/2016/03/31/andalucia/1459439248_383505.html

Manzano, Eduardo, 2018. "El Affaire de la Mezquita de Cordoba." El País, Abril 13, 2015 https://elpais.com/elpais/2015/02/05/opinion/1423137778_840752.html

Morán Breña, Carmen. 2015. “Cien expertos critican la situacion de la Mezquita de Cordoba." El País, Noviembre 3, 2015. https:// elpais.com/politica/2015/11/03/actualidad/1446553126_305752.html 
Rebollo Puig, Gabriel, Ruiz Cabrero, Gabriel, and Sebastián Herrero. 2013. "La Catedral es una catedral (y II)." ABC Seville, Septiembre 23, 2013. https://www.abc.es/cordoba/20130923/ sevp-catedral-catedral-20130923.html
"The Mosque in the Cathedral." 2015. The Economist, October 8, 2015. https://www.economist.com/europe/2015/10/08/the-mosque-inthe-cathedral 


\section{TEXTO ORIXINAL}

\section{Architecture, Memory, and the Future: the Mosque-Cathedral of Cordoba*}

Michele Lamprakos

University of Maryland-College Park

Cordoba is a city of ghosts. Of course, it could be said that Spain is a country of ghosts, but the effect is heightened in the south, the site of so much of the nation's pathos. Since the late nineteenth century, these ghosts have haunted modern attempts to save the city's heritage and to attract tourism. An historic zone was identified for protection as early as 1912; the aim, in the words of the mayor, was

to perpetuate and sustain, to the extent possible, the typical character of our population in the districts which, through the classic structure of their streets and the aspect of the overall ensemble, evoke the memory of extinguished races and the events of distant eras, and excite the curiosity of those who visit it.'

When the heritage project started, these "extinguished races," Muslims and Jews, had been absent from the peninsula for hundreds of years. They were forcibly converted and ultimately expelled in the early modern period — part of the process of creating a unified and fully Catholic state. ${ }^{2}$ These absent presences haunt the city and surrounding landscape: unusual church layouts, indebted to the plans of the mosques on which they are built; minarets hidden within bell towers; buildings rumored to be synagogues; street names that evoke the city's Arab-Islamic past, and others that recall the atrocities of the Inquisition. But some of the ghosts are more recent: empty monasteries seized by the Liberal state in the nineteenth century; beheaded statues in churches attacked by anti-clerical rioters during the Civil War; the unmarked graves of victims of Franco's reign of terror. The so-called "pact of forgetting, " which accompanied Spain's transition to democracy, in a sense characterizes the whole of Andalusian history. ${ }^{3}$ History —or rather particular histories — have been repeatedly buried, only to be partially excavated, then buried again in a new cycle of forgetting.

A remarkable building stands in the heart of Cordoba, as if in defiance: the so-called MezquitaCatedral, the "Mosque-Cathedral" (fig. 1). One of the great monuments of world architecture, it is the city's claim to fame: the source of its pride, wealth, and anxiety. Although the building has been a cathedral for almost eight centuries, most locals still refer to it as "la Mezquita." In recent years, the Church has tried to change that. A dispute has been raging between the Church and citizen activists over the control and meaning of the building. The intensity of the dispute is surprising to outsiders, especially given the pressing problems of the region: in particular, a desperate economic situation that has left a generation without work and an insecure future, fueling yet another wave of Andalusian migration to other parts of Spain and beyond. Only gradually does one become aware that the conflict over the Mezquita is as much about the present as it is about the past. Indeed, the two are inextricably intertwined. The back-story of the conflict is made up of interlocking threads - all of which can be traced, directly or indirectly, to layers in the building itself.

The Mezquita is the most magnificent of the Friday or congregational mosques that were the center of religious and civic life under Islamic rule, which lasted in various forms on the peninsula for some seven centuries (eight-fifteenth centuries). When Castilian forces conquered cities (eleventh-fifteenth centuries), they consecrated mosques for Christian worship. Eventually they demolished them and built cathedrals - a process that mirrors the appropriation of sacred Christian sites by Muslims in Spain and elsewhere. ${ }^{4}$ But Cordoba's Mezquita survived. Over the centuries, it was modified for Catholic worship, culminating in the insertion of a massive choir and presbytery in the sixteenth century (the structure is 
usually called a coro-crucero, or simply crucero, "transept"). Christian interventions responded to the structural, spatial, and symbolic qualities of the mosque. As at other cathedrals, these interventions were motivated by new liturgical needs and changing tastes. ${ }^{.}$But this is not just any cathedral. It is a cathedral housed in the former Great Mosque of Cordoba - a building that symbolizes Islam at the height of its power in Europe. Throughout the centuries, the Mezquita has been a place of worship, a beloved monument, and also a potent reminder of the Islamic past. We can read cycles of patronage, demolition, and restoration as an index of changing attitudes toward that past and the specter of the Moor: a recurrent image of self and other in Spanish history. ${ }^{6}$

\section{A Building "Unique in the World"}

The Great Mosque was constructed in several phases under the Umayyad dynasty which, exiled from Syria, established a powerful empire on the Iberian peninsula (eight-eleventh centuries). The original mosque of Abd al-Rahman I (784-785) was twice extended by moving the qibla wall to the south, toward the river; with al-Mansur's expansion to the east (circa 987), the mosque reached an unprecedented size (fig. 2).? Each addition continued the original structure and morphology: two tiers of arches, with alternating red brick and white stone voussoirs, run perpendicular to the qibla wall; the arches are in turn supported by marble columns of various colors, reused from ancient sites or newly fabricated. ${ }^{8}$ The result is a fantastic, maze-like interior that presents the visitor with endless and constantly shifting vistas (fig. 3). In later centuries, Spanish chroniclers never failed to describe the space as a "forest of columns", tacitly highlighting the contrast with the more finite and hierarchical forms of church architecture. The hypostyle plan is anchored in the southwest quadrant by al-Hakam's magnificent addition, completed in 976. The three bays of the maqsura (royal enclosure) correspond to three arched openings in the qibla wall; the central and largest arch frames the mihrab, which takes the form of a small room. The bays of the maqsura and the entry bay at the head of the addition are covered with skylit domes, and partially screened by intertwined arches. This basilica-like configuration has precedents in both palace and church architecture (fig. 4). ${ }^{9}$

When Ferdinand III took Cordoba in 1236, the mosque was consecrated as a church through well-established rituals of purification, and dedicated to the Virgin Mary; several years later, it was made a cathedral. ${ }^{10}$ For two and a half centuries, Christian ceremonial and patronage would focus on al-Hakam's addition, perhaps because the architecture, decoration, and symbolism were reminiscent of a church. As Muslims had conceived of the al-Hakam basilica as a "mosque within a mosque," so Christians seem to have seen it as a "church within a church." "It has been assumed that the direction of prayer was changed immediately to the east, but the location of the dedication ceremony is unknown. Some historians place the first cathedral choir in the nave in front of the mihrab, with an altar dedicated to San Pedro. Only after 1257, under the patronage of Alfonso X, was a capilla mayor built in al-Hakam's vestibule, with the altar facing east (fig. 5).12 For over three centuries, the sacred host would be stored in the mihrab, and the Santa Maria parish would worship in the mihrab nave - praying toward the south, as Muslims had. ${ }^{13}$

The Mezquita's unlikely survival — the subject of much speculation by both specialists and nonspecialists - is usually attributed to its great beauty and prestige. ${ }^{14}$ In his mid-fifteenth century description of the city, a Cordoban monk extolled the building as

a temple worthy of all manner of praise, whose spectacular beauty reanimates the spirit of whoever contemplates it. It is the glory of Spain and distinctive symbol of the honor of Cordoba, illustrious seat of its Bishop; a monument that honors the kings who exacted such injurious revenge, a revenge that make us shed tears for its ancient owners...

Certainly, the artistic construction of such a great edifice will move men to admiration, when they contemplate the multitude and height of its marble columns. The talent of the architects determined an extreme structural clarity, so that wherever one looks, his gaze marches on majestically... 
"What can we say of this famous temple?" continues the monk, "The historians refer to the prodigious attributes of only seven buildings in the world.... But who will appreciate in the future these monuments as superior to others, when contemplating such a temple in our city?" 15 The Mezquita, then, was lauded by both Christians and Muslims as one of the wonders of the world. It was the great exemplar of the Hispano-Islamic style — the "high style" of the day- and became a model for churches as well as mosques, on the Iberian Peninsula and beyond.

For two and a half centuries, the Mezquita enjoyed royal protection and patronage - notably the fourteenth century Royal Chapel, a celebrated example of mudejar architecture. ${ }^{16}$ This started to change with the resumption of "Reconquista" in the late 15th century and the gradual consolidation of a unified and Catholic Spain. With the fall of Granada imminent, Cordoba's bishop, Iñigo Manrique de Lara (1485-1496), proposed a plan to transform the Mezquita. The project, allegedly opposed by Queen Isabel, may have ended in a compromise: a Gothic-style nave was carved out in the area of al-Hakam's addition, extending westward from the altar (fig. 6). ${ }^{17}$ In the following decades, the flush of military victory and economic boom made it possible to build grand new cathedrals; some of these were on the sites of mosques that had been recently seized in Andalusia. ${ }^{18}$ Seville's massive cathedral, on the site of the old Almohad Friday mosque, had been under construction for over a century, and was nearing completion. It was against this backdrop that Bishop Alonso Manrique de Lara (1516-1523; first cousin of Iñigo) made a second proposal to transform the Mezquita. When demolition started in late spring of 1523, the Town Council launched a massive protest, appealing all the way to Emperor Charles V. The project eventually went forward, perhaps scaled down from the original plan. When the emperor saw the demolition in 1526, he reportedly said:

Had I known what this was, I would not have allowed it to reach the ancient part, because you have done what could be done anywhere; and you have undone that which is unique in the world. ${ }^{19}$

Charles's apocryphal comment may derive from the Town Council's statement of 1523: the new project, they wrote, would destroy a temple that was "unique in the world." 20

The massive crucero, when it was completed a century later, would transform the image of the building on the skyline (fig. 7). But within the building, the fabric of the mosque, rather curiously, appeared to remain intact. A close inspection reveals that the initial architect, Hernán Ruiz I, wrapped the crucero in a new "ambulatory": he replicated some of the Islamic-era arches he had demolished, reusing the same stones, columns, and capitals. ${ }^{21}$ The substitution of new work for old is only evident when one looks up at the ribbed vaults, or notices discrete decorative details. In effect, Hernán Ruiz I disguised the crucero on the inside, softening the new and alien insertion (figs. 8 and 9). This produced a curious dual image, which has confused, disturbed, and fascinated visitors over the centuries: the building is a cathedral, but it looks like a mosque.

For centuries to come -indeed, to the present day — visitors and chroniclers have repeated Charles's apocryphal comments, regretting that this unique building had been victimized. But some, like a seventeenth century diplomat from Morocco, reported that the mosque had remained essentially unchanged.22 Indeed, visitors continued to extol the endless vistas of the mosque, which did not seem compromised by the crucero. Today, defense of the crucero implicates one in an ideological debate. But it is rarely noted that Hernán Ruiz I's sensitive insertion preserved both the reading of the mosque and the memory of a conflict - at the very moment when the Muslim presence and cultural legacy were being erased from the peninsula.

\section{From Christianization to "Re-islamicization"}

The altar of the crucero was dedicated in 1607, shortly before the descendants of Muslims, or "Moriscos," were expelled. ${ }^{23}$ In the mid-1600s, the base of the tenth century minaret — which had been converted into a bell tower- would be wrapped in stone, and eventually lost to memory. In 
the eighteenth century, an elaborate choir stall (sillería) was completed; the red and white voussoirs of the arches were whitewashed; and baroque-style vaults and lanterns (/ucernarios) were installed, infusing the space with light and more thoroughly integrating the crucero (figs. 10 and 11). ${ }^{24}$ The "christianization" of the mosque fabric seemed complete. But in the nineteenth century, afrancesado bishops and later, state architects, would begin to recover the Islamic fabric. They revealed the mihrab; demolished the baroque vaults; stripped whitewash from the arches; and removed chapels, retablos, and tombs. The magnificent portals of the east façade were restored and partially reconstructed in the early twentieth century, reestablishing the Islamic image of the building in the city (fig. 12). ${ }^{25}$ These restorations made it possible for contemporaries to envision the building as a mosque - just as Romantic artists had, replete with Muslims praying in front of the mihrab (fig. 13). Much of the Islamic fabric we see today is the product of these nineteenth and twentieth century restorations (figs. 14 and 4).

The process of "re-islamicization," ${ }^{26}$ which lasted for a century and a half, had political undertones. For some Liberals, the figure of the Moor was a hero, a rebel, an enlightened ruler who presided over a flourishing, diverse society before it was destroyed by a fanatic alliance of Church and State. ${ }^{27}$ In effect, they celebrated the Islamic past because it was not the Church. After the building was declared a national monument (1882), the provincial monuments commission, staffed by a Liberal and sometimes anti-clerical cultural intelligentsia, worked with state architects to recover the Islamic fabric. Their demolition of layers of Christian history was sometimes supported, and sometimes contested, by Church officials who needed state funds to maintain and repair the massive structure.

Recovery of the Islamic fabric also intersected in surprising ways with Spain's imperial ambitions in North Africa, and with regional identity politics. In the 1930s, inspired by the restored Islamic image of the Mezquita and in response to calls by Arab nationalists, some Republicans argued that Muslims should again be allowed to pray in the building; others wanted to turn it into a museum. There was even a proposal to remove (trasladar) the crucero entirely, and reconstruct the missing Islamic parts. Then in 1936 Nationalist troops rose up against the Republic; General Francisco Franco crossed the strait of Strait of Gibraltar with the help of Moroccan legionnaires. Paradoxically, Franco - champion of National Catholicism - took up the old Republican idea: he sought to turn the Mezquita back into a mosque, as a way to thank to the Islamic world for its support. ${ }^{28}$

Thus the Mezquita became a diplomatic pawn in the dictator's Arab policy which, after Moroccan independence (1956), aimed at strengthening economic ties with the Arab world. The traslado proposal was in play behind the scenes for decades, finally erupting in a huge and very public controversy in the waning years of the regime. Spear-headed by Rafael de la Hoz Arderius, General Director of Architecture (1971-3), with support from Cordoba's mayor Antonio Alarcón, the Ayuntamiento, and members of the cultural and professional elite, the idea was to "purify" the Mezquita in preparation for nominating it to the new World Heritage list. Traslado was debated in the press and in the pages of Arquitectura, Spain's most prestigious architectural journal. Government agencies generally supported the proposal, but it was opposed by the Church and independent cultural institutions notably the San Fernando Royal Academy of Fine Arts, the body that had historically been charged with oversight of patrimony. In 1973, at an ICOMOS conference held at the Mezquita, traslado was apparently defeated. Invoking the 1964 Venice Charter, Church and ICOMOS representatives argued that the crucero was an important architectural layer —and evidence of religious and cultural coexistence (convivencia). ${ }^{29}$ But in the following years, echoes of the traslado controversy continued to reverberate on the shifting political landscape.

\section{The Mezquita in Transition}

In the 1970s, the Mezquita became a performative space for a new ecumenical spirit. Two IslamoChristian Congresses were held there (1974 and 1977), bringing together eminent theologians and scholars to discuss the historical relationship of the two faiths, and to chart a course of peace and 
mutual understanding. Islamic congregational prayer (salat) and Catholic Mass were held in the Mezquita, with members of each faith attending the other's service. Meanwhile traslado was still being discussed behind the scenes, part of a massive project to turn Cordoba into a kind of museum-city of Arab-Islamic civilization. Financed by Arab states and brokered by UNESCO, the initiative ultimately died — like so many projects before and after that sought to highlight the city's Islamic heritage.

In the 1980's, the century-long project to re-islamicize the Mezquita was finally completed: the last artesanado ceilings were installed, with the exception of the eastern zone (al-Mansur's addition) where $18^{\text {th }}$ century plaster vaults were retained, preserving that layer of Christian history. In 1984, a plan by Rafael Moneo Vallés and Gabriel Ruiz Cabrero established new criteria for restoration. Echoing the recommendations of the 1973 ICOMOS meeting, they argued that it was necessary

to accept the Mosque of Cordoba as and how it has arrived to our days, coming to terms with its rich and complex history. Its present state demonstrates the consistency of the architecture of the first mosque, capable of assimilating numerous and varied interventions without losing its integrity. ${ }^{30}$

A new era had begun, reversing the long endeavor to recover the original Islamic space. ${ }^{31}$ That same year, the Mezquita was one of five monuments added to the World Heritage list. But the nomination dossier, prepared by the new Andalusian regional government and the General Directorate of Fine Arts, attributed no value to the Christian layers. Rather, the "Mosque of Cordoba" - as the monument was called - was valued exclusively for its attributes as mosque.

It might be expected that, with transition to democracy and freedom of religion, there would be a new openness to the Islamic past in Cordoba. But in fact, the opposite has occurred. We have been witnessing a new wave of "christianization" at the Mezquita, as Church authorities have sought to downplay, discredit, and even deny the Islamic past.

Once again, we can only understand this phenomenon in historical perspective. The end of the Franco regime reopened a culture war between conservative Catholic and anti-clerical forces, which had been forced underground after the Civil War. An increasingly conservative Church has seen its privileges and social base eroded. Political devolution (from 1978) allowed regional governments to write their own histories: in Andalusia, this has meant vindicating and celebrating the Islamic past, ${ }^{32}$ often in opposition to the Church. Meanwhile, real Muslims returned to the peninsula, as immigrants, tourists, and converts. Converts to Islam — not immigrants - have repeatedly sought authorization to pray in the Mezquita, even appealing to the Vatican. ${ }^{33}$ Spanish converts, in particular, see the building as "their heritage" —a heritage which, like Islam itself, had been forcibly wrenched from their ancestors.

The Mezquita, then, once again became a battleground with high symbolic stakes. In the early 1990s, the Church began a campaign to remove the word "mezquita" from the building's official name. ${ }^{34}$ A few years later, al-Qaida broadcast its first threats to "retake" al-Andalus —claims that seemed terrifyingly real after the Madrid train bombings (2004). ${ }^{35}$ Over the course of that decade, Church authorities began to rewrite the building's history through archeological exhibits, brochures, and interpretive programming that emphasize the Christian "origins" of the site, and discredit the Islamic legacy (fig. 15). ${ }^{36}$ It has even been suggested that the mosque is a derivative building -late Hellenistic or Byzantine- denying not only the originality of Hispano-Islamic civilization, but its cultural legacy. ${ }^{37}$ Meanwhile, the crucero was carefully restored. In a sense reversing the traslado project, the restoration has given the crucero a new prominence: it now appears whiter and brighter thanks to cleaning and window replacement (fig. 16). The restoration architects argue that this more accurately reflects the original architects' intentions: the luminous crucero was not merely additive, they say, but rather transformed the nature and meaning of the building. ${ }^{38}$ The surrounding mosque fabric - now darker in contrast - has been increasingly dedicated to exhibit space: stripped of spiritual meaning, Islamic or Christian. Yet some altars and statues have been reintroduced, at the very spots where they had been removed —as recently as the 1980s (figs. 17 and 18). 
In 2009, an uproar ensued when it was revealed that Cordoba's bishop had registered the Mezquita in his name three years earlier. This was just one, albeit highly symbolic, of thousands of properties discreetly registered by Church authorities under a Franco-era law, which was amended in 1998 to include houses of worship. ${ }^{39}$ Citizen activists fought back, challenging what they see as yet another attempt to erase historical memory. In late 2013, they launched an international petition asking UNESCO and the Andalusian government to assert public control over the Mezquita, as a national monument and a World Heritage site. ${ }^{40}$ They were supported by a hundred prominent academics from thirty-six universities in Spain and abroad, in a manifesto that criticized Church policies and supported public ownership. ${ }^{41}$ Critics noted that the Church collected enormous revenues from ticket sales, but paid no taxes; meanwhile, it received public funds for restoration projects and interpretive programming, with no government oversight, which allowed it to "colonize" the space and control the historical narrative. Not only were Church authorities to blame, but public agencies which seemed incapable of action. ${ }^{42}$ Not for the first time, observers held up the Town Council's defense of the Mezquita in 1523 as an example - the only time in history that civil authorities had stood up to the Church.43

In spring 2014, conservative Minister of Justice Alberto Ruiz-Gallardón declared in the Senate that the Mezquita belonged to the Church. UNESCO steered a middle course, confirming that the building is a cathedral —a living religious site — but upholding the name Mezquita, since the building was listed as a World Heritage site in 1984 for its attributes as a mosque. The situation shifted with the formation of a leftist city government in 2015: the new mayor, Isabel Ambrosio, vowed to return title to the public domain. The Church agreed to keep the word mezquita in the building's official name, but maintained that it was the historic and rightful owner. ${ }^{44}$ In 2017 an expert commission was formed to study the question of ownership, led by Federico Mayor Zaragoza, former General Director of UNESCO. The commission's report, released in September 2018, presents an historically grounded case for public ownership, and argues for joint management of the monument. The report had immediate repercussions in the press, provoking a predictable counter-offensive by the Church and its supporters. ${ }^{45}$ But it comes at a highly sensitive moment, as public indignation mounts over the Church's registrations (inmatriculaciones). Assessing their legitimacy and reversing those that are illegal would be a daunting task for the courts. ${ }^{46}$ The Mezquita has become a flashpoint, yet again, for larger battles in Spanish society. But notably absent from the discussion is a curious and fundamental question: why do we lack basic historical information about the Mezquita, when such documentation exists for other monuments in other cities?

\section{Architecture, Memory, and the Future}

In recent decades, convivencia has become a kind of brand - and also the sincere aspiration of those who see Cordoba as a model for a multicultural Europe. Yet the Mezquita complicates this myth too, as it has defied so many other myths and projections. The Church's campaign to change the building's name and discredit the Islamic legacy has been embarrassing to some - out of keeping with Spain's image as a modern European state. ${ }^{47}$ Once again, unresolved questions about the past erupt, the suppressed contents of a cultural imaginary: a vicious circle of maurophobia and maurophilia that has more to do with projections of self than with real Muslims. ${ }^{48}$

Over the course of its life, the Mezquita has been a theater where identities are performed and contested. But it has also been a protagonist in the drama. The Great Mosque projected the power of Umayyad rulers and, from the tenth century, their claim to the caliphate across the Mediterranean world. After the fall of Cordoba, the building came to symbolize the loss of al-Andalus, which would be lamented over the centuries by Muslims. ${ }^{49}$ For Christians, it was an architectural wonder and a trophy. But by the late fifteenth century, in an era of cathedral building and renewed war against the Muslims, the Mezquita must have been seen by some in the Church hierarchy as an uncomfortable anomaly. Sited prominently on the banks of the Guadalquivir River - once a front line in the Reconquista, now the heart of a World Heritage site - the Mezquita continues to provoke questions that official culture 
has ignored or suppressed. Today, despite widespread international attention, few have noted that the current conflict is ultimately about architecture. The dual nature of the building evokes that old, but still potent, debate about the nature of Spanish identity and legacy of the Islamic past. Was the Islamic era, as some argue, simply a parenthesis in the history of Spain? Do modern-day Spaniards embody a primordial, Christian-European essence that miraculously survived, "uncorrupted" by Arab-Islamic culture? Or was the Islamic era fundamental in shaping Spanish culture and identity? In other words, are Muslims "other" or "us"?

The struggle over the Mezquita has polarized a community and paralyzed historical inquiry. It is crucial to establish new terms for the debate - a debate that is being followed around the world, at a time of escalating radicalization and polemics about the alleged "clash of civilizations." Over the course of its life as a cathedral, and later, as an historic monument, interventions reveal something about how contemporaries saw the Islamic past —as elite, ancient, alien, threatening, heroic, pacified, or exotic. As such, they tell us something about how contemporaries saw themselves, relative to the real or imagined other. The material layers of the Mezquita have sometimes been used to further various ideological agendas. But a careful and sober study of these layers, however incomplete or reconstituted, will tell us more: confounding ideology and complicating easy answers. The layers tell a complex story with multiple actors, motivations, and interests that have played out in this sublime space: a story which, unlike written texts, cannot be fully suppressed or erased. 
NOTES

* I am grateful to the many individuals in Cordoba, Seville, Madrid, and elsewhere who have generously shared their knowledge, insights, and documents; and to the editors of Quintana for their translation and guidance. I also want to thank the following institutions for their assistance and support: the Faculty of Philosophy and Letters, University of Cordoba, and its library; the Bishop's Chapter and Archive of the Cathedral of Cordoba; the Municipal Archive, the Municipal Office of Urban Management, Diario CÓRDOBA, the Provincial Historical Archive, the archive of the Archeological Museum, and the Casa Árabe, all in Cordoba; the San Fernando Royal Academy of Fine Arts, Madrid; the UNESCO Archives, Paris; and the Graduate School and the School of Architecture, Planning, and Preservation, University of MarylandCollege Park. Photos were taken by Cornelia Steffens in 2015 unless otherwise noted. An earlier version of this article appeared in P. Karimi and N. Rabbat, eds., The Destruction of Culture Heritage in the Middle East: from Napoleon to ISIS. Aggregate Architectural Collaborative website, volume 3, December 2016; http://we-aggregate.org/piece/ memento-mauri-the-mosque-cathedralof-cordoba

1 Salvador Muñoz Pérez, motion presented to the Ayuntamiento, January 15, 1912. Cited in F.R. García Verdugo, "Los inicios del pensamiento conservacionista del casco histórico de Córdoba (1835-1958)," In Córdoba: Patrimonio Cultural de la Humanidad: una Aproximación Geográfica, ed. López Ontiveros and Naranjo Ramírez (Córdoba: Ayuntamiento de Córdoba, 1996), 131.

2 Jews were given the choice between conversion and expulsion in 1492. Muslims were given a similar choice over the course of the 16th century; enforcement varied from place to place. Fears of incomplete assimilation of the "Moriscos," as converted Muslims came to be called, and their alleged sympathy to the Ottomans, led to their final expulsion in 1609. See M. Carr, Blood and Faith: The Purging of Muslim Spain (New York and London: The New Press, 2009).
3 The "pact of forgetting" (pacto de olvido) was a decision by parties on both the right and left to refrain from settling scores after Franco's death in 1975. For the pact of forgetting as remembering, see Javier Cercas, Anatomy of a Moment (New York: Bloomsbury, 2011), 91-93.

4 The great mosques of Toledo, Jaen, Seville, Murcia, Granada, and other cities were used as cathedrals for varying periods of time, before they were demolished and replaced. A similar process occurred with smaller neighborhood mosques that were used as parish churches, and eventually replaced. For an overview of the process see S. Calvo Capilla, "De mezquita a iglesia: el proceso de cristianización de los lugares de culto de al-Andalus," In P. Giráldez and M. Vendrell, eds., Trasformació, destrucció i restauració dels espais medievals (Barcelona: Patrimoni2.0 Consultors, 2016): 129-148; J. Kroesen, "From Mosques to Cathedrals: Converting Sacred Space during the Spanish Reconquista," Mediaevistik 21 (2008): 113-137; P. Buresi, "Les conversions d'églises et de mosquées en Espagne au Xle-XIlle siècles," In Religions et Sociétés au Moyen Âge: Études offertes à Jean-Louis Biget par ses Anciens Élèves, réunies par P. Boucheron et J. Chiffoleau (Paris: Publications de la Sorbonne, 2000), 333-350; J. Harris, "Mosque to church conversions in the Spanish Reconquest," Medieval Encounters 3.2 (Leiden: Koninklijke Brill, 1997): 158-172; J. Orlandis, "Un problema eclesiástico de la reconquista española: la conversión de mezquitas en iglesias cristianas," Mélanges offerts à Jean Dauvillier (Toulouse: Centre d'histoire juridique méridionale, 1979), 595-604. See also Heather Ecker, "From Masjid to Casa-Mezquita: neighbourhood mosques in Seville after the Castilian conquest, 1248-1643." (PhD diss., Oxford University, 2000). For Muslims' appropriation and periodic demolition of churches, see Buresi and also J. Dodds, Architecture and Ideology in Early Medieval Spain (University Park: Penn State Press, 1989), 60-66. A tradition holds that Cordoba's Great Mosque was built over the ruins of a Visigothic basilica that Muslims had shared for a time with Christians, but the archeological evidence is inconclusive. For a recent historiographical review, see F. Arce-Sainz, "La supuesta basílica de San Vicente en Córdoba: de mito histórico a obstinación historiográfica," Al-Qantara 36.1 (January-February 2015): 11-44.

5 R. Moneo, "La Vida de los Edificios," Arquitectura 256 (SeptemberOctober 1985): 27-36; A. Capitel, "La Catedral de Córdoba: transformación cristiana de la Mezquita," Arquitectura 256 (1985): 37-46. An account of the modifications is provided by $\mathrm{M}$. Nieto Cumplido, La Catedral de Córdoba (Córdoba: Obra Social y Cultural de CajaSur, 2007). For the late Islamic and early Christian periods, see H. Ecker, "The Great Mosque of Cordoba in the Twelfth and Thirteenth Centuries," Muqarnas 20 (2003): 113-141. On the crucero as a reflection of new tastes, see A. Urquízar Herrera, "La Memoria del Pasado en la Cristianización de la Mezquita de Córdoba durante la Edad del Humanismo," In Correspondencia e Integración de las Artes, $14^{\circ}$ Congreso Nacional de Historia del Arte, vol. 1, ed. I. Coloma Martín and J-A Sánchez López (Málaga: Ministerio de Educación, Cultura, y Deportes/Dirección de Cooperación y Comunicación Cultural, 2003).

$6 \mathrm{H}$. Kamen, The Disinherited: The Exiles Who Created Spanish Culture (London and New York: Allen Lane/ Penguin Books, 2007), chapter two; J. A. González Alcantud, Lo Moro: las lógicas de la derrota y la formación del esterotipo islamico (Rubí, Barcelona: Anthropos Editorial, 2002), chapter four.

7 Nineteen aisles, with 33 bays in each aisle; Robert Hillenbrand, "The use of spatial devices in the Great Mosque of Cordoba," Islâo e Arabismo na Peninsula Ibérica, Actas do XI Congreso da U.E.A.I. (Evora: Universidade, 1982), 184. The following account is indebted to Hillenbrand's analysis.

8 The literature on the mosque is enormous. See S. Calvo Capilla, Las Mezquitas de al-Andalus (Almería: Fundación Ibn Tufayl de Estudios Arabes, 2014), 84-108; for concise accounts in English, see J. Dodds, "The Great Mosque of Cordoba," In Al-Andalus: The Art of Islamic Spain (New York: Metropolitan Museum of Art, 1992), 11-26; and N. Khoury, "The Meaning of the Great Mosque of Cordoba in the Tenth 
Century," Muqarnas 13 (1996): 80-98. The stages of the mosque's evolution were proposed by Amador de los Rios in 1879. For a more nuanced view, see Ecker, "The Great Mosque of Cordoba in the Twelfth and Thirteenth Centuries," 113-115.

9 Possible precedents for the form include royal reception rooms at Madinat al-Zahra and Mozarabic churches in northern Spain (J. Dodds, Architecture and Ideology, 94-106; S. Calvo Capilla, Las Mezquitas de al-Andalus, 87.) Dodds links al-Hakam's addition to Christian symbolism and ritual. On this topic see also O. Grabar, "Notes sur le mihrab de la Grande Mosquée de Cordoue," In Le Mihrab dans I'Architecture et la Religion Musulmane, ed. A. Papadopoulo (Leiden: E. J. Brill, 1988), 115-122; and Robert Hillenbrand, "'The Ornament of the World': Medieval Cordoba as Cultural Centre," In The Legacy of Muslim Spain, ed. S. K. Jayyusi and M. Marín (Leiden; New York: E.J. Brill, 1992), 134-135.

10 The mosque had been converted into a church on an earlier occasion, in 1146, when Castilian forces briefly held the city; they dedicated it to the Holy Cross of Jerusalem. When Muslims retook Cordoba, they converted it back into a mosque. See Ecker, "The Great Mosque of Cordoba in the Twelfth and Thirteenth Centuries," 116-117; Nieto Cumplido, La Catedral de Córdoba, 329-338. When mosques were converted into churches, they were usually dedicated to the Virgin Mary, the patroness of the Reconquista. (J. Kroesen, "From Mosques to Cathedrals," 115; J. Harris, "Mosque to church conversions," 165).

11 Ecker, "The Great Mosque of Cordoba," 120-121, building on Khoury's analysis ("The Meaning of the Great Mosque," 89). Ecker hypothesizes that it was the proximity of the sabat, a covered bridge to the old caliphal (now episcopal) palace, which determined the location of the capilla mayor.

12 M. Muñoz Vázquez, "Vicisitudes de la Mezquita-Catedral de Córdoba," In La Mezquita de Córdoba: empeño universal (Córdoba, 1973), 50; I. Sanz Sancho, Geografía del Obispado de Córdoba en la Baja Edad Media (Madrid,
1995), 58. Nieto Cumplido and others believe that the church was consecrated under the dome of al-Hakam's vestibule, based on a partial inscription from 1236 that survives in the dome. See Nieto Cumplido, La Catedral de Córdoba, 449-450; and Corpus Mediaevale Cordubense (Cordoba: Monte de Piedad y Caja de Ahorros de Córdoba, 1979), 1 : 87, doc. 162

13 This parish "church"or sagrario was moved to the southwest corner of the building in 1586, while the crucero was under construction. The term sagrario refers to the place where the host is kept; and also to a chapel within some cathedrals that serves as church for the surrounding parish.

14 See, for example, Antonio Almagro's comparison of the fates of the Cordoba mosque and the Friday mosque of Seville: "De Mezquita a catedral: una transformación imposible," In La Piedra Postrera: V Centenario de la conclusión de la Catedral de Sevilla, vol. 1, ed. A. Jiménez Martín (Seville: Cabildo Metropolitano, 2007), 13-47.

15 Descriptio Cordovbae, written circa 1450 by "Jerónimo," possibly a canon at the Royal College of San Hipólito, Cordoba. The text is partially transcribed from the Latin by M. Nieto Cumplido in La Catedral de Córdoba, 319-320. In Nieto's earlier transcription, he writes "antiguos bárbaros" rather than "antiguos poseedores" (Córdoba en el Siglo XIV, Córdoba: Tip. Católica-Ing. Torres Quevedo, 1973, 67).

${ }^{16}$ Mudéjar refers to Muslims living under Christian rule, and also to the Islamicate arts produced under Christian rule for Christian, Muslim, and Jewish patrons. On the Royal Chapel see M.A. Jordano Barbudo, El Mudéjar en Córdoba (Córdoba: Diputación Provincial, 2002), 117-129; and La Sinagoga de Córdoba y las yeserías mudéjares en la Baja Edad Media (Córdoba: Servicio de Publicaciones Universidad de Córdoba, 2011), 139-161.

17 L. Torres Balbás, La Mezquita de Cordoba y las Ruinas de Medinat al-Zahra (Madrid: Editorial Plus-Ultra, 1952), 105-106. This formalized the area which for two and a half centuries had accommodated the choir of the bishop's chapter.
18 J. Harvey, The Cathedrals of Spain (London: B. T. Batsford, Ltd., 1957), 58, 223.

19 As reported by Juan Gómez Bravo, canon of Cordoba, in 1739 (Catálogo de los obispos de Córdoba, y breve noticia histórica de su iglesia catedral, y obispado, 1778 edition, vol. 1, 419420).

20 Libro de Actas Capitulares, 29 April 1523, Municipal Archive of Cordoba, C-2122/43. A real provisión dated 14 July 1523 suggests that the royal appeals court (audiencia) had found in favor of the city and may have suspended work, at least for a time. See M.A. Ortí Belmonte, "Oposición del cabildo municipal de Córdoba a la construcción del crucero de la Mezquita," Boletín de la Real Academia de Córdoba año XXV, no. 70 (Enero-Junio): 271-277

21 G. Ruiz Cabrero, Dibujos de la Catedral de Córdoba: Visiones de la Mezquita (Barcelona: Cabildo Catedral de Córdoba/This Side Up, 2009), 49. For an analysis of Hernán Ruiz I's intervention see A. Capitel, "La Catedral de Córdoba"; and J. Lorda Iñarra and M.A. Martínez Rodríguez, "El primer proyecto de Hernán Ruiz para la Catedral de Córdoba," In Actas del Séptimo Congreso Nacional de Historia de la Construcción, Santiago 26-29 octubre 2011, ed. S. Huerta et al. (Madrid: Instituto Juan de Herrera, 2011), 791-798. For an overview of the construction process see $M$. Nieto Cumplido, La Catedral de Córdoba, 503-525.

22 J. Aranda Doncel, "La mezquita de Córdoba a través de los viajeros extranjeros de los siglos XVII y XVIII," Homenaje a Manuel Ocaña Jiménez (Córdoba: Imprenta San Pablo, 1990), 35-36.

${ }^{23}$ Philip III issued an edict of expulsion in 1609; for the debate leading up to the decree, see Carr, Blood and Faith, chapter 17.

24 The vaults remain in place in the eastern part of the building; Gabriel Ruiz Cabrero, restoration architect, argued for their preservation in the 1980s.

${ }^{25}$ The east façade was one of several projects conducted in the early 20th century by Ricardo Velázquez Bosco, the first state-appointed restoration architect. See G. Ruiz Cabrero, "Dieciséis 
proyectos de Ricardo Velázquez Bosco. La Mezquita-Catedral de Córdoba," Arquitectura 256 (1985): 47-56.

26 The term "re-islamicization" is Ecker's.

${ }^{27}$ On the Moor as rebel, see $\mathrm{H}$. Kamen, The Disinherited, 72.

28 In 1972, in the midst of a new attempt to remove the crucero, art historian Marqués de Lozoya Lozoya (Juan de Contreras y López de Ayala) wrote: "More than thirty years ago, when I was Director General of Fine Arts [19391951] the idea arose, as a gesture of gratitude toward the Islamic world, which had so effectively contributed to victory, to disassemble and move the Gothic-Renaissance cathedral of Cordoba, restoring the Mezquita to its stylistic integrity and ancient destiny, so that it would become, as it had been in the $10^{\text {th }}$ century, the spiritual center of Islam. I opposed it then, insofar as I was able, and I was fortunate to have been heard" ("La Islamización de la Mezquita no Remediaría Nada," Diario Ya, November 7 , 1972).

29 For two different accounts of these events see Nieto Cumplido, La Mezquita de Córdoba y el ICOMOS (Córdoba: Servicio de Publicaciones del Excmo. Ayuntamiento, 1976); and J.I. Cassar Pinazo, "Annotaciones al artículo 'Datos para la restauración de la Mezquita de Córdoba,' Rafael Castejón y Martinez de Arizala," Papeles de Partal. Restauración Monumental 2 (November 2004): 17-44. For recent accounts of the traslado controversy, see F. Daroca Bruño, "Córdoba 1950, Rafael de LaHoz como motor de la modernidad." (PhD thesis, Universidad de Sevilla, July 2017): 136-153; S. Herrero, De lo original a lo auténtico. La restauración de la Mezquita Catedral de Córdoba durante el siglo XX (Córdoba: Cabildo Catedral de Córdoba, 2017): 223-233; and M. Lamprakos, "Recovering the Great Mosque of Cordoba: the History of an Idea" (forthcoming 2019).

${ }^{30}$ R. Moneo Vallés and G. Ruiz Cabrero, "Proyecto de restauración de la Mezquita-Catedral de Córdoba," 1984, cited in S. Herrero, De lo original a lo auténtico, 257.

${ }^{31}$ S. Herrero, De lo original a lo auténtico, 245.
32 See M. Díaz-Andreu, "Islamic Archeology and the Origin of the Spanish Nation," In Nationalism and Archeology in Europe: an Introduction, ed. M. DíazAndreu and T. Champion (London: UCL Press, 1996), 86.

${ }^{33}$ These attempts date back to the early 1980's; see J. Roberson, "From Dictatorship to Democracy: Cordoba's Islamic Monuments in the Twentieth Century," In Rethinking Place in South Asian and Islamic Art, 1500-Present, Rebecca R. Brown and Deborah S. Hutton, eds. (Abingdon and New York: Routledge, 2017), 128-130.

34 In its plenary session of 1994 Cordoba's Ayuntamiento approved the hyphenated name "Mezquita-Catedral"; interview, Mayor Herminio Trigo (1986-1995), June 2018. When the World Heritage listing was expanded in 1994 to include the surrounding context, the question of the building's name was side-stepped: at the suggestion of the Spanish delegate, the site was called simply "Historic Centre of Cordoba" (UNESCO Archives, Paris, CLTMHC/ NOM 135).

$35 \mathrm{H}$. Aidi, "The Interference of al-Andalus: Spain, Islam, and the West," Social Text 87, 24:2 (Summer 2006): 81-84.

36 For example, display of the alleged remains of the Basilica of San Vicente beneath the mosque floor; see footnote 4 and figure 15 .

37 See Nieto Cumplido's introduction to the 2007 edition of La Catedral de Córdoba, 13-20; and his recent book, La Mezquita de Córdoba, Joya Bizantina (Córdoba: Cabildo de la Santa Iglesia de Córdoba, 2016). Cordoba's bishop, Demetrio Fernández, supports this thesis: "So, in reality, the Umayyads, the caliphs, didn't have their own architects, nor did they create a new art, it's not Muslim art. They went to their Christian countrymen in Damascus, and brought them to Cordoba. But the art isn't Muslim, it's Byzantine...it's Byzantine Christian. The Moors (sic) only put up the money" (Bishop Demetrio Fernández, interview, Revista 17: un análisis del estado de cultura en Córdoba, December 2016, 107). In the same interview, the bishop denied that Church authorities had tried to remove the word "mezquita" from the building's name, although he himself had advocated it; see 'La Catedral de Córdoba,' $A B C$ Córdoba, Octubre 10, 2010, 48.

The Church's attempts to discredit and even deny the Islamic past at the Mezquita is part of a wider, newly reinvigorated debate over the legacy of Islam on the peninsula — a debate that dates back to at least the $19^{\text {th }}$ century. On this topic see A. García Sanjuán, "Rejecting al-Andalus, exalting the Reconquista: historical memory in contemporary Spain,' Journal of Medieval Iberian Studies, 10:1, 2018, 127-145; and La conquista islámica de la Península lbérica y la tergiversación del pasado: del catastrofismo al negacionismo (Madrid: Marcial Pons, 2013).

38 G. Rebollo, G. Ruiz Cabrero, and S. Herrero, "La Catedral es una catedral (II)," ABC Seville, Septiembre 23, 2013, accessed October 17, 2018, http://seviIla.abc.es/cordoba/20130922/sevp-catedral-catedral-20130922.html. On the restoration of the crucero see $\mathrm{S}$. Herrero, De lo original a lo auténtico, 285-8; and G. Rebollo Puig and G. Ruiz Cabrero, "El crucero 'restolado', " Patrimonio Cultural de España, 2010, no. 4, 151-163.

39 The 1946 Ley Hipotecaria allowed Church representatives to register buildings, lands, and even public spaces as private property, but not houses of worship. The law was modified in 1998 under the Aznar government to allow registration of houses of worship. Buildings were often registered without proof of title, and without the knowledge of civil authorities. The privilege was terminated in 2015, but not made retroactive. See "Clarificar la Propriedad," El País, Septiembre 10, 2018, accessed 17 October, 2018: https://elpais.com/elpais/2018/09/10/ opinion/1536605389_931290.html

$40 \quad$ https://www.change.org/p/ salvemos-la-mezquita-de-córdoba-poruna-mezquita-catedral-de-todos. The petition was launched by the Plataforma Mezquita - Catedral de Córdoba: Patrimonio de tod@s, established in 2013. For background on the dispute see especially E. Calderwood, "The Reconquista of the Mosque of Cordoba," Foreign Policy, April 10, 2015; and B. Jover Báez and B. Rosa, "Patrimonio cultural en disputa: la Mezquita-Catedral de Cór- 
doba," Cuadernos Geográficos 56:1, 2017, 322-343.

41 "Cien expertos critican la situación de la Mezquita de Cordoba," El País, Noviembre 3, 2015, accessed October 11, 2018: https:// elpais.com/politica/2015/11/03/actualidad/1446553126_305752.html. See also Eduardo Manzano's opinion piece, "El Affaire de la Mezquita de Cordoba," El País, Abril 13, 2015, accessed October 11, 2018: https:// elpais.com/elpais/2015/02/05/opinion/1423137778_840752.html

42 Tour guides, for example, are vetted by the Church: they can only bring groups into the Mezquita after passing a special test, assuring adherence to the authorized narrative.

43 In a public address in 1921, Antonio Jaén Morente, historian, lawyer, and Republican politician, said: "Only once, at the dawn of the sixteenth century when the Cathedral chapter, having carried out a mistaken proposition, built a Christian cathedral after tearing the Moorish mosque to pieces, did the Town Council raise its voice a little, attempting to oppose the outrage; and the words of its proclamation will always be their honored and illustrious gift: 'we order that no builder, stonemason, carpenter, or laborer dare to touch the said work, on pain of death'... Since then, nothing" (A. Jaén Morente, "El problema artístico de la Ciudad de Córdoba," Conferencia pronunciada en el Círculo Mercantil por iniciativa de la Junta de Defensa y Progreso, 10 Diciembre 1921 (Córdoba: Imprenta Moderna, 1922), 8-9).
44 See "The Mosque in the Cathedral," The Economist, October 8, 2015, accessed October 11, 2018, https://www.economist.com/ europe/2015/10/08/the-mosque-inthe-cathedral; "El Cabildo insta a resolver por vía jurídica la titularidad de la mezquita," El País, marzo 21, 2016, accessed October 11, 2018, https:// elpais.com/ccaa/2016/03/31/andalucia/1459439248_383505.html

45 Forty-three academics, largely specialists in medieval history, signed a document dismissing the commission's report: "Mas de 40 historiadores se rebelan contra el informe del Consistorio sobre la Mezquita-Catedral de Córdoba," $A B C$ Córdoba, Septiembre 23, 2018 (accessed 17 October 2018), https://sevilla.abc.es/andalucia/cordoba/ sevi-cuarenta-medievalistas-denuncianinforme-mezquita-cordoba-careceminimo-rigor-201809221052_noticia. html. Rafael Sánchez Saus, Catedrático de Historia Medieval de la Universidad de Cádiz, known for his extreme right views, was the driving force behind the document. Among the signators is Serafín Fanjul, chief exponent of ultraconservative views on al-Andalus in contemporary Spanish historiography.

Alejandro García Sanjuán, Profesor de Historia Medieval, Universidad de Huelva and member of the expert commission, responded to attempts to discredit the commission's report, elaborating on the historical argument against Church ownership. The argument is based on two main points: first, there is no documentary evidence that Ferdinand III gave the Mezquita to the Church; and second, it was the norm for seized mosques to remain property of the king, who could dispose of them as he saw fit. The norm is documented in the Siete Partidas, legal codes from the era of Alfonso X, son and successor of Ferdinand III. See A. García Sanjuán, "La propiedad de la Mezquita de Córdoba: una historia tergiversada" https:// www.eldiario.es/andalucia/enabierto/ propiedad-Mezquita-Cordoba-historiatergiversada_6_816528342.html; and Ibid., "¿Donó Fernando III la Mezquita de Córdoba a la Iglesia en 1236?," AlAndalus y la Historia, Septiembre 26, 2018, http://www.alandalusylahistoria. $\mathrm{com} / ? \mathrm{p}=580$

46 At the time of this writing, the PSOE government was preparing to release a list of properties registered by the Church, a compromise it obtained while in the opposition ("Clarificar la Propriedad," El País, Septiembre 10, 2018).

47 On embarrassment as an ingredient of national identity see M. Herzfeld, Cultural Intimacy: Social Poetics of the Nation State (New York: Routledge, 2005), 3-6.

48 See J.A. González Alcantud, El mito de al Andalus: Orígenes y actualidad de un ideal cultural (Editorial Almuzara, 2014), chapter two. On the role of maurophobia in the current conflict, see Calderwood, "The Reconquista of the Mosque of Cordoba".

49 N. Khoury, "The Meaning of the Great Mosque of Cordoba in the Tenth Century," 80. 